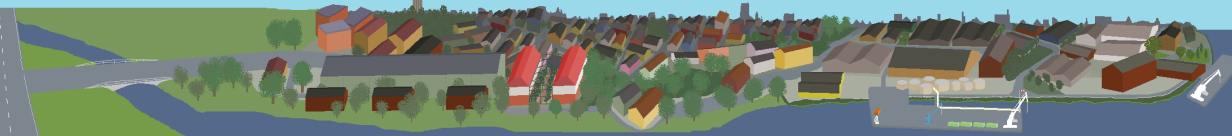

Linköping Studies in Science and Technology

Dissertation No.2169

$V_{m=1}=$

Tा

Decision-making and

decision support connected

to biogas use in Sweden

\title{
Sofia Dahlgren
}

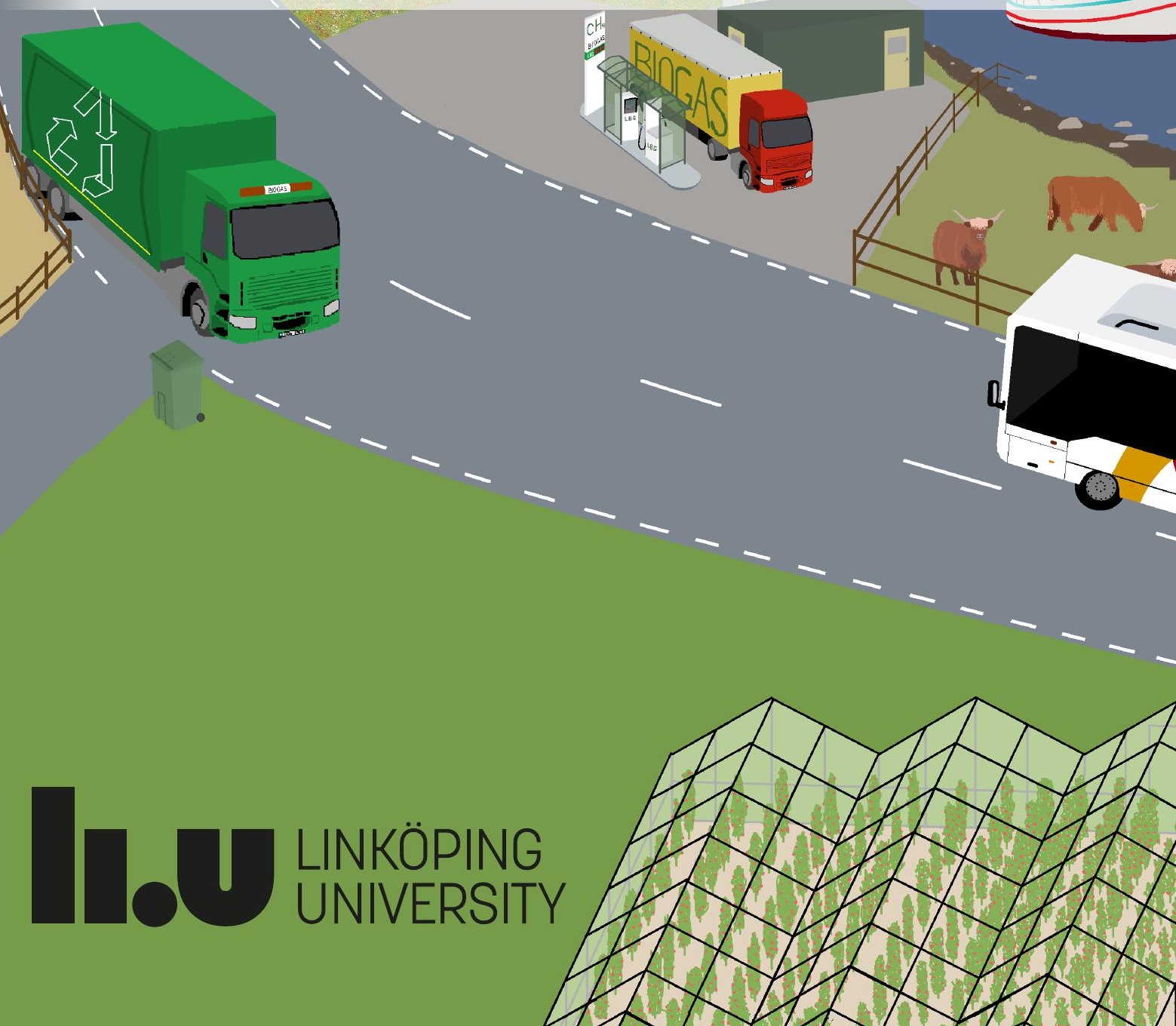





\section{Decision-making and decision support connected to biogas use in Sweden}

Sofia Dahlgren 
(cc) EY-No Detta verk är licensierat under en Creative Commons ErkännandeIckeKommersiell 4.0 Internationell Licens.

https://creativecommons.org/licenses/by-nc/4.0/

\author{
(c) Sofia Dahlgren
}

Decision-making and decision support connected to biogas use in Sweden Linköping Studies in Science and Technology

Dissertation No. 2169

ISBN 978-91-7929-022-1

ISSN 0345-7524

Printed in Sweden by LiU Tryck, 2021

Cover design: Sofia Dahlgren

Distributed by:

Linköping University

Department of Management and Engineering

SE-581 83 Linköping, Sweden 


\section{Abstract}

Human activities cause many sustainability challenges in the world, which need to be dealt with. One way to decrease the negative impacts related to those challenges is by replacing currently dominating technologies with better, alternative technologies. However, such shifts are not easy to achieve - for example, each new user has to make a decision to start using the technology.

The aim of this thesis is to contribute to a greater understanding of what the decisions to use alternative technologies are based on and how the decisions can be supported. In order to achieve this aim, the thesis focuses on the decisions of private companies' and public organizations in Sweden of whether or not to use biogas in Sweden. The thesis is based upon six appended papers, which are used for addressing three research questions: How do biogas compare to other potential alternatives? Why do decision-makers in Sweden find it interesting to use biogas, and what makes them hesitant? And, how can decision support be used in decision-making to deal with complexities connected to biogas decisions?

It is concluded that biogas has environmental and social advantages compared to several other renewable alternatives, but that it can be more expensive. The technical maturity of biogas use depends partly upon the usage area - biomethane buses is a mature area while heavy trucks is less mature. Biogas is perceived by decision-makers as a good environmental option and a better long-term solution than several other renewable alternatives since there are investments done and since the policymakers seem positive towards biogas. Public organizations tend to look at the broader positive aspects of biogas, such as energy security and nutrient recovery, while private companies tend to be more focused on biogas as an environmental action that can benefit the image of the company. However, decision-makers can be hesitant towards biogas due to economic or policy aspects or a lack of technical maturity. The decision-makers can also experience a lack of knowledge that makes them uncertain about biogas. Decision support can help the decision-makers in different ways, with different tools being more suitable for different parts of the complexities connected to biogas decisions. Multi-criteria assessments can help the decision-maker focus on several impacts at once and making the decision process transparent for trade-offs, while socio-technical scenarios can help the decision-maker understand how the wanted changes can be realized. 


\section{Sammanfattning}

Mänskliga aktiviteter orsakar många hållbarhetsproblem i världen, vilka behöver hanteras för att vi ska få en hållbar värld och ett hållbart samhälle. Ett sätt att hantera dessa problem och minska den negativa påverkan vi människor har är att byta till att använda bättre tekniker istället för de tekniker som används idag. Sådana förändringar är dock inte helt enkelt att vare sig genomföra eller påverka, och för att öka användningen av en bättre teknik måste till exempel varje ny användare ta ett beslut om att använda tekniken.

Målet med den här avhandlingen är att hjälpa till att öka kunskapen om beslut kring att använda bättre tekniker - vad sådana beslut är baserade på och hur sådana beslut kan stödjas. Fokuset $\mathrm{i}$ avhandlingen är framförallt på ett specifikt fall - företags, kommuner och regioners beslut att använda biogas i Sverige. Avhandlingen innehåller sex vetenskapliga artiklar, som tillsammans hjälper till att svara på tre frågor. Hur skiljer sig biogas från andra potentiella alternativ? Varför är beslutsfattare intresserade av att använda biogas, och vad gör dem tveksamma? Hur kan beslutsstöd användas för att hjälpa beslutsfattarna att hantera komplexa delar i beslut kopplade till biogas?

Resultaten visar att biogas har miljö- och samhällsfördelar i jämförelse till flera andra förnybara alternativ, men att biogas kan vara dyrare. Hur bra teknik det finns och hur väl den fungerar beror lite på användningsområde - biogas har använts för bussar ganska länge vilket gör att tekniken är mer välutvecklad där, medan det är ganska nytt att använda biogas i tunga lastbilar som ska köra långa sträckor. Beslutsfattare uppfattar att biogas är ett bra miljöalternativ, och att det är en bättre långsiktig lösning än flera andra förnybara bränslen eftersom investeringar görs i biogas och eftersom de som beslutar om regler och stöd för förnybara bränslen verkar positiva till biogas. Kommuner och regioner tenderar att titta mer på fler positiva saker kring biogas, till exempel att man kan producera energi från lokala råvaror och att biogasproduktionen kan hjälpa till med att återanvända näringsämnen. Företag å andra sidan tenderar att fokusera mer på att biogas kan användas som en miljöåtgärd som kan förbättra bilden av företaget hos allmänheten. Beslutsfattare kan dock tveka kring att använda biogas på grund av ekonomiska anledningar, eller att lagarna och stöden för biogas inte är optimala, eller då tekniken inte är tillräckligt välutvecklad för det företaget vill använda biogas till. Det finns även beslutsfattare som inte har så mycket kunskap om biogas, vilket gör att de är mer osäkra kring att använda det. Beslutsstöd kan hjälpa beslutsfattare på olika sätt, med olika verktyg som passar för olika situationer och olika svårigheter. Multikriterieanalys kan användas för att hjälpa beslutsfattare att fokusera på flera olika typer av påverkan samtidigt och göra beslutsprocessen enkel att förstå så att beslutsfattarna kan besluta vilka typer av påverkan som ska prioriteras. Sociotekniska scenarier kan å andra sidan hjälpa beslutsfattare att förstå hur de ska lyckas med att genomföra de förändringar som de vill införa. 


\section{Acknowledgements}

My greatest thank you goes to my supervisors, who has helped me on this journey. My main supervisor Stefan Anderberg, who has guided me during these five years and who is always ready to answer a question, comment on a text or simply discuss how everything is going. Jonas Ammenberg, who has only been my supervisor during the last two years but who I have learnt a lot from during this time, as well as from the projects and articles we have been doing together. And Thomas Magnusson, whom I worked with more during my first couple of years as a $\mathrm{PhD}$ student but who still comes with very insightful comments.

I also want to thank the enablers of this research. The partners of the Biogas Research Center, who, apart from funding my research, also have been a network that have helped making my research better. Vinnova and the European Regional Development Fund, who have also funded my research. All the people that have been involved as part of workshops, student projects, interviews, revisions and so on.

Also - thank you to all my wonderful colleagues at the Division of Environmental Technology and Management. When I am writing this, I have been working from home during the last one and a half years. I miss you guys, and hope that we will soon be able to spend time together in real life and not only through video chats. The Lunch and Fika crew - Carina, Maria, Linda, Axel, Marcus, Madeleine, Anna and so on. I miss those lunches and fikas, when any and all subjects could be discussed. My office mate Tharaka - though I guess we haven't really used the office that much during these last one and a half years. The head of our division Olof, who in some way manages to keep our division on fairly the right track - it is not a task I envy you, but I think you do it admirably. Our administrator Maria, without whom we would all be lost. My previous and current unit leaders, Sara and Wisdom, who tackles the task of keeping our unit together, even though we, at times, work in quite different areas from each other. Wisdom, who also managed to guide me through the process of writing and publishing my first article. All the PhD students (and those of you who aren't PhD students any longer) who have helped me in my journey through answering questions, discussing matters or, at times, simply listening when I needed to talk - Linda, Axel, Marianna, Johannes, Venus, Sergio, Jay-El, Raphael, Tharaka, Filip, Eman and so on. And all the seniors, whose knowledge I have learnt a lot from during these years - Carina, Mats, Olof, Sara, Niclas, Marcus, Roozbeh, Annica, Murat, Jocke, Mattias, Tom and so on.

I have no partner and no children to acknowledge in this last part of the acknowledgment. However, that does not mean that I don't have a family. I want to say a big thank you to my closest family - my mother, my sisters, my father and his wife, my grandparents, my aunt and her partner. And lastly, concluding the same way as I did in the acknowledgments in my licentiate thesis, I want to give an extra thank you to my non-human family members. My horses, who make sure that I am outdoors and moving even at times that I might otherwise be holed up indoors with the computer. My chicken, who keep me with a fresh supply of eggs and a fresh supply of flowerbeds that needs to be repaired. And, most importantly, my dogs. Samantha, who is always by my side if I am home. And Cinder, who has learnt that making sure I can't see the computer screen is a great way to get attention. 


\section{List of appended papers}

\section{Paper I:}

Dahlgren, S. (2020). Biogas-based fuels as renewable energy in the transport sector: an overview of the potential of using CBG, LBG and other vehicle fuels produced from biogas. Biofuels. https://doi.org/10.1080/17597269.2020.1821571

\section{Paper II:}

Dahlgren, S., Kanda, W., \& Anderberg, S. (2019). Drivers for and barriers to biogas use in manufacturing, road transport and shipping: a demand-side perspective. Biofuels.

https://doi.org/10.1080/17597269.2019.1657661

\section{Paper III:}

Dahlgren, S., Ammenberg, J. Environmental considerations regarding freight transport among Swedish transport buyers. Manuscript

\section{Paper IV:}

Ammenberg, J., Dahlgren, S. (2021). Sustainability Assessment of Public Transport, Part IA Multi-Criteria Assessment Method to Compare Different Bus Technologies. Sustainability, 13, 825. https://doi.org/10.3390/su13020825

\section{Paper V:}

Dahlgren, S., Ammenberg, J. (2021). Sustainability Assessment of Public Transport, Part IIApplying a Multi-Criteria Assessment Method to Compare Different Bus Technologies. Sustainability, 13, 1273. https://doi.org/10.3390/su13031273

\section{Paper VI:}

Magnusson, T., Anderberg, S., Dahlgren, S., \& Svensson, N. (2020). Socio-technical scenarios and local practice - Assessing the future use of fossil-free alternatives in a regional energy and transport system. Transportation Research Interdisciplinary Perspectives, 5, 100128. https://doi.org/10.1016/j.trip.2020.100128 


\section{Definitions and abbreviations}

Biogas. A mix of mainly methane and carbon dioxide produce from the anaerobic digestion of organic matter. Biogas is used as a term when the focus is on how the gas is used, even if part of that use is by upgrading it to biomethane. The term biomethane is used when only biomethane is meant.

Biomethane. Biogas that has been cleaned/upgraded so that the methane content in the gas is at least $97 \%$.

CBG. Compressed biomethane, that is, upgraded biogas that has been pressurized to $200 \mathrm{bar}$ in order to reduce the needed volume. Also known as CBM, RNG (renewable natural gas), or bio-CNG.

FAME. Fatty acid methyl ester. A type of biodiesel. High blends of FAME requires small changes to the diesel vehicles.

HVO. Hydrotreated vegetable oil. A type of biodiesel that can be used in most diesel vehicles without any changes to the vehicle.

LBG. Liquefied biomethane, that is, upgraded biogas that has been cooled down to $-162^{\circ} \mathrm{C}$ in order to turn the gas into a liquid. Also known as LBM or bio-LNG.

MCA. Multi criteria assessment.

RME. Rapeseed methyl ester. A type of FAME-biodiesel. High blends of RME requires small changes to the diesel vehicles. 


\section{Table of Contents}

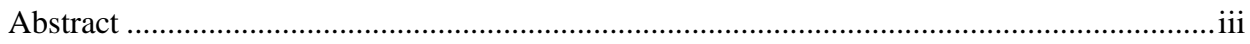

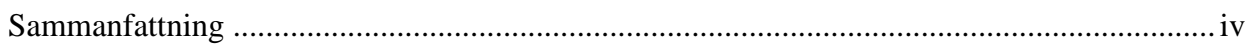

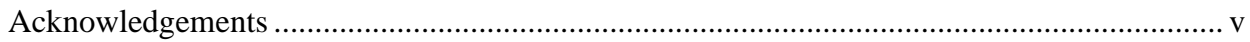

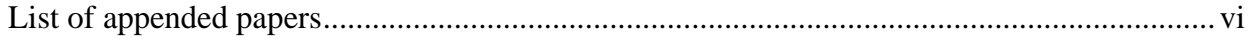

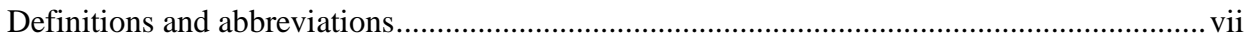

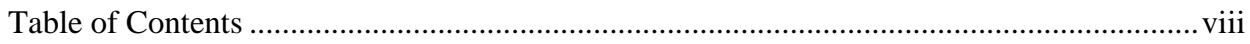

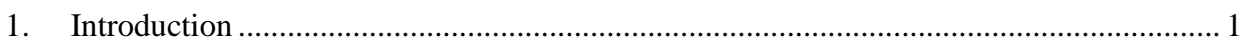

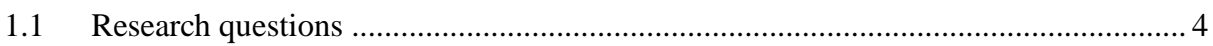

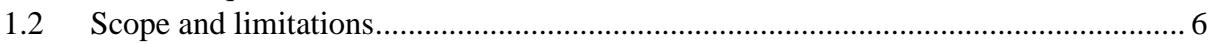

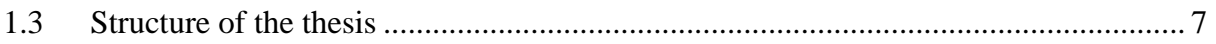

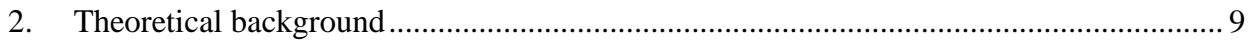

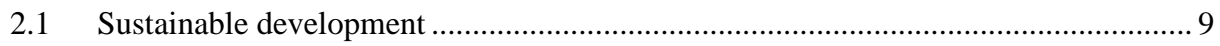

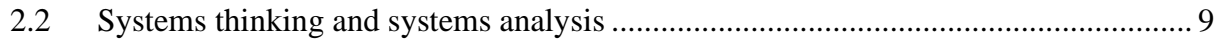

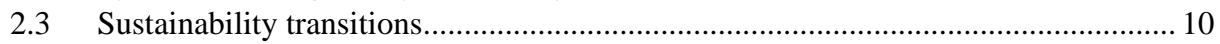

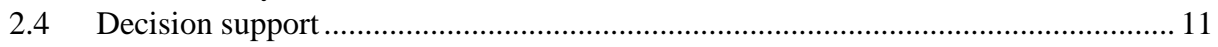

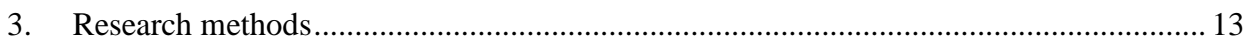

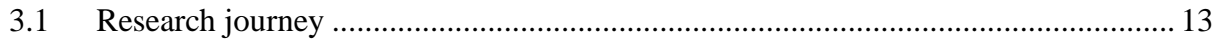

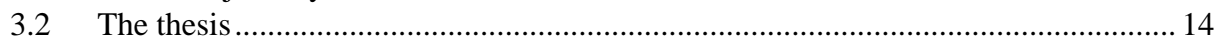

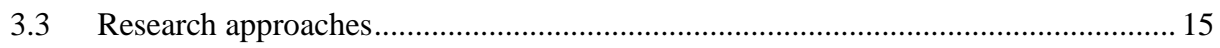

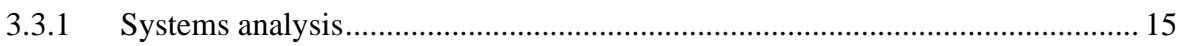

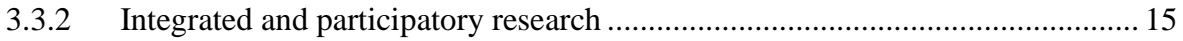

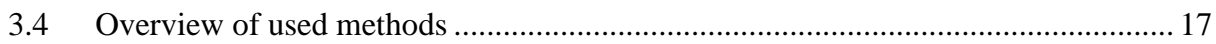

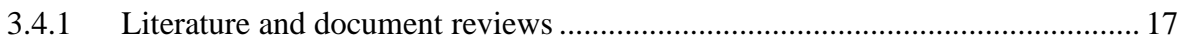

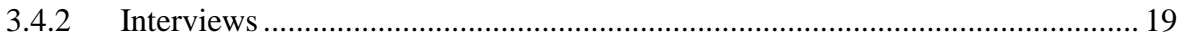

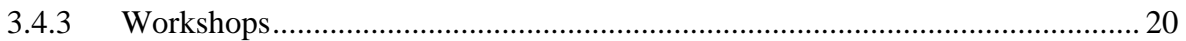

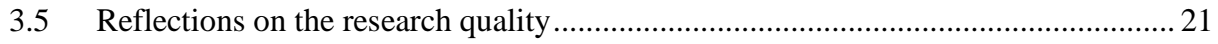

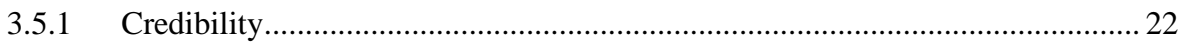

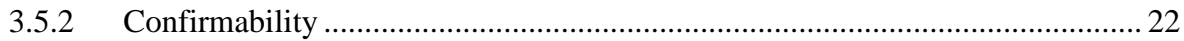

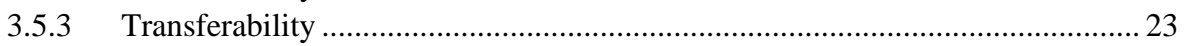

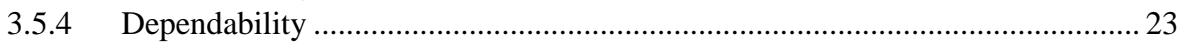

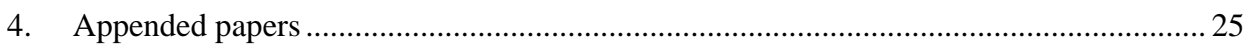

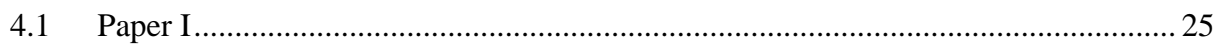

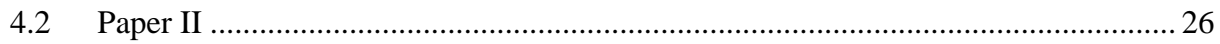

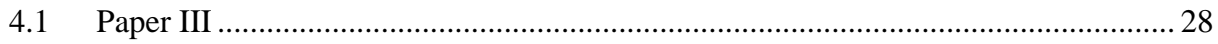

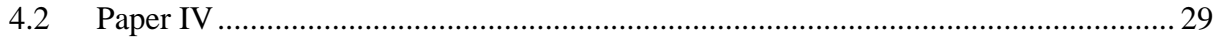

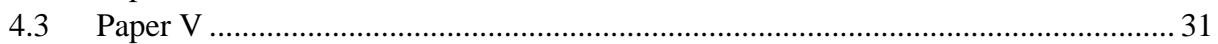

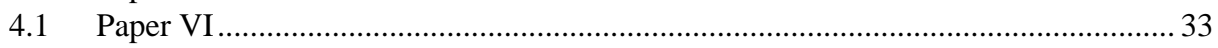

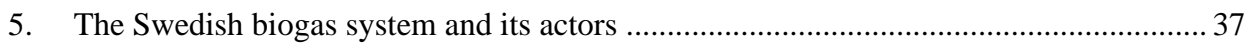


5.1 What biogas systems include

5.2 Different kinds of raw materials, production plants and usage areas ......................... 37

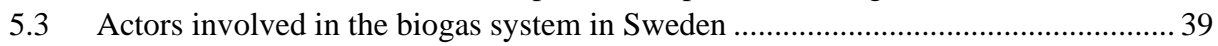

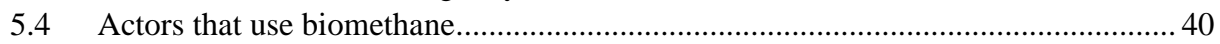

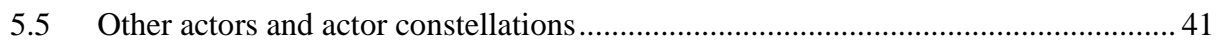

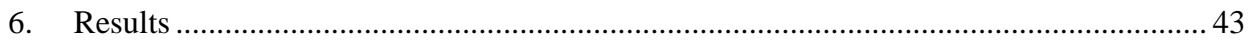

6.1 How biogas compares with other potential alternatives ......................................... 43

6.2 Why decision-makers in Sweden are interested in or hesitant towards biogas ......... 45

6.3 How decision support can be used in decision-making to deal with complexities ... 48

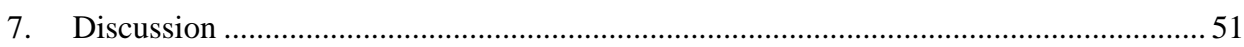

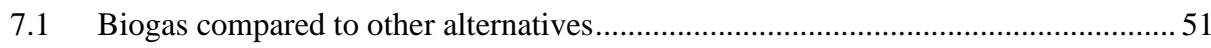

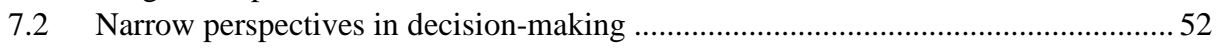

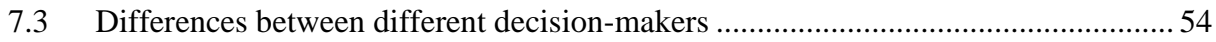

7.4 Dealing with sustainability issues when there is no completely good alternative to

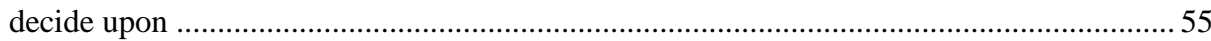

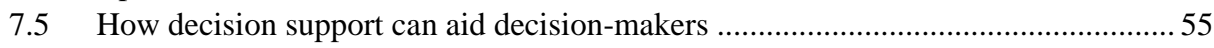

7.6 Implications connected to transition management ….............................................. 56

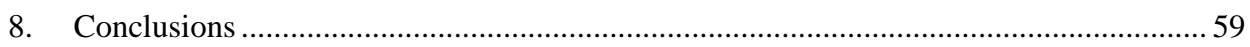

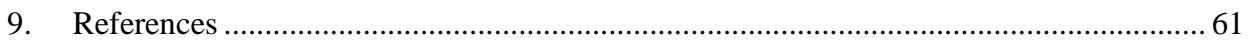




\section{Introduction}

The world today is facing many sustainability problems that have large negative impacts on society and the environment (UN General Assembly 2015), such as climate change (Pachauri, Mayer, and Intergovernmental Panel on Climate Change 2015) and unsustainable use of nutrients (Smith, Tilman, and Nekola 1999; Vitousek et al. 1997). One way to reduce negative impacts is by changing from technologies and socio-technical systems with more negative impacts to "better" technologies and socio-technical systems that have less negative, or even positive, impacts. A difficulty, however, is that technologies and socio-technical systems may have different types of impact, and to "be good" in only one or a few aspects is not enough. There often seems to be a one-sided focus on climate change together with maybe a few other problems (Kügemann and Polatidis 2019). This can be problematic since sustainability challenges are wicked problems (Brown et al. 2010), and it is impossible to find solutions that are good from all viewpoints (Rittel and Webber 1973) - there is no final solution that deals with the challenge without causing any other problems (Bernstein 2015) For example, using a solution that reduces one problem can instead increase other problems, also known as problem shifting (Baumgartner and Korhonen 2010). Focusing on reduced greenhouse gas emissions can, for example, lead to increased problems with resource depletion and toxicity (Laurent, Olsen, and Hauschild 2012). Using a broad perspective can be a way to address several challenges simultaneously by finding solutions that contribute positively to more than one of the challenges, so-called multifunctional solutions (Lindfors et al. 2019).

Such solutions can be alternative technologies, which can replace currently dominating unsustainable, often fossil-based, technologies. In order to get a large positive effect, it is not enough that only a few users change to the alternative technology - instead, there should be a shift in society to a new normal state that the better technology is part of. However, such shifts with a radically increased use of more sustainable technologies can be difficult to achieve. There has been an increasing amount of research done on how such changes in society occur (Köhler et al. 2019), with a focus on issues such as moving away from fossil fuels (Geels et al. 2017; Klitkou et al. 2015) and how new technologies can become mainstream (Smith and Raven 2012; Sushandoyo and Magnusson 2014). There is, however, a need for more research on how to manage later phases, when the technologies have already been introduced and the use needs to expand (Köhler et al. 2019). Managing changes towards better options is not something that can be done top-down by a government in isolation; instead, it is recognized that a number of both public and private actors need to contribute at different levels of society (Köhler et al. 2019). Governing for sustainable development requires approaches and actions across many levels, scales and sectors (Fenton and Gustafsson 2017). The focus in the research is still often at a large-scale societal level, but many small changes towards using the technology are needed to introduce and accelerate the use of a technology. Each new user, and actor influencing the use, has to make a decision to start using the technology.

This decision, however, is not necessarily easy to make or influence. It can be difficult to know what alternative is the most suitable in a specific situation, making it difficult for decisionmakers to know the best alternative for them. Decision-makers can have several different alternatives to choose between, which means they have to prioritize and decide between the alternatives (Lundmark et al. 2021), and several previous studies have highlighted that there is a need for guidance and support in connection with, for example, green purchasing or 
procurement (Cheng et al. 2018; Guenther et al. 2013; Testa et al. 2016). The decision-makers deciding upon whether or not to use a technology can have different motives (Bergek and Mignon 2017) and see different challenges with adopting the technology (Mignon and Bergek 2016). There might also be policies in place that encourage or discourage their use (Huttunen, Kivimaa, and Virkamäki 2014). This thesis addresses such difficulties by studying whether or not to use an alternative technology and what influences decisions to use or not to use an alternative technology. The thesis looks at what the decisions are based on (what advantages and disadvantages are connected to using a particular technology) and how the decisions can be supported via decision support method.

Aim
The aim of this thesis is to contribute to a greater understanding of what the
decisions to use or not use alternative technologies are based on and how these
decisions can be supported.

This aim is addressed via studies related to the biogas systems in Sweden. Biogas systems are based on anaerobic digestion and the subsequent production and use of biogas, an energy-rich gas that mainly consists of methane and carbon dioxide, and digestate, a nutrient-rich sludge. Historically, anaerobic digestion started to be used in Sweden as a part of treating wastewater (Fallde and Eklund 2015), but later on decision-makers also started to be interested in the biogas and the digestate produced in the anaerobic digestion processes. The anaerobic digestion process can help treat the organic waste of different kinds, the digestate can be used as fertilizer, and the biogas can be used as a renewable fuel in heat or electricity production or as a vehicle fuel after upgrading to biomethane (Wellinger, Murphy, and Baxter 2013). Such systems decrease several different negative impacts compared to the technologies currently being used (such as mineral fertilizers or fossil fuels) and even have some positive impacts (Hagman and Eklund 2016).

However, even though biogas systems have many benefits, the main revenue in the biogas system in Sweden is from the sale of the biogas - the use of the biogas is thus currently a prerequisite for making the biogas system work. In contrast to the rest of the world, where biogas is primarily used for power or heat (Cappannelli et al. 2020), it is primarily upgraded to biomethane and used as vehicle fuel in Sweden (Klackenberg 2020). Biomethane has been used as vehicle fuel in Sweden since the 1990s (Fallde and Eklund 2015) and Sweden accounted for $70 \%$ of the biomethane used for transport in the EU in 2015 (Scarlat, Dallemand, and Fahl 2018). In recent years, however, several other countries are also moving towards upgrading biogas to biomethane so that it can be used in vehicles (Association Technique Energie Environment 2018; Bachmann 2013; Baier, Buchs, and Hermle 2018; Danish Energy Agency 2017; Huttunen, Kuittinen, and Lampinen 2017; Theobald 2015).

Previous research has found that biogas systems are important for a large-scale change towards more renewable energy (Wirth et al. 2013). In contrast to many other renewable fuels, it is possible to produce energy using a wide variety of waste resources, such as livestock manure, sewage, food waste and crop residues, as well as other resources like energy crops (Jain et al. 2019; Lantz et al. 2007) and microalgae (Raheem et al. 2018). Using waste resources is often 
considered a better environmental option than using energy crops (e.g. Lijó et al. 2017; Prussi et al. 2020), and the current biogas production in Sweden is almost exclusively based on waste resources (Klackenberg 2020). However, energy crops are common substrates for biogas production in the rest of the world (Cappannelli et al. 2020), leading to some legitimacy problems in countries such as Germany, where the production is mainly based on energy crops (Magnusson and Berggren 2018). Those legitimacy problems do not exist in Sweden (Magnusson and Berggren 2018), and the Swedish government seems to be generally positive towards biogas systems and started an inquiry in 2018 on how the advantages of biogas systems can be used best and how biogas systems can be given competitive conditions through longterm stable rules (Swedish Government Official Reports 2019).

Geels and Raven (2007) found that competition between small-scale farm-based production plants and large-scale centralized production plants might affect a change towards more biogas. According to Markard et al. (2009), biogas is still a radical innovation due to its decentralized nature even though it is a mature technology. Several previous studies on biogas systems have focused on a larger scale like national changes (Negro, Hekkert, and Smits 2007), how historical changes have occurred (Geels and Raven 2006, 2007), or policies (Huttunen et al. 2014), but there has been less focus on "small changes" and on particular actors within the system and their decisions. There are a few, such as Ammenberg et al. (2018) or Fallde et al. (2015), but the focus of research on biogas use is primarily on a larger scale.

A challenge with biogas systems is that they can be more complex than other bioenergy systems due to several factors influencing the system in different ways and that a large number of different actor are involved (Lantz et al. 2007). This challenge is not simply due to the sheer number, but also that the actors and diverse and can be situated in different sectors (e.g., agriculture or energy) (Huttunen et al. 2014; Lantz et al. 2007; Wirth et al. 2013) - meaning that the biogas systems have to be aligned and embedded with actors and practices in multiple sectors (Wirth et al. 2013). This is not necessarily unique for biogas systems since there is a diversity of actors involved in competing alternatives, but biogas systems are an example that is clearly situated in multiple sectors rather than only one.

The interdependent nature of systems means that different parts of the system are connected and that changes in one part will mean changes to other parts accordingly (Hughes 1987). A decision-maker thus cannot decide to use biogas completely alone without ensuring that the other involved actors are part of the change, at least not without negatively affecting the system - and the diversity of involved actors thus have to work together. According to Lundmark et al. (2021), effective actor-networks that work towards a common goal are essential for establishing local biogas systems.

Decisions related to the use of biogas, however, are complex for more reasons than only based on the involved actors. Even though there is a large potential to increase the anaerobic digestion and production of biogas (Swedish Waste Management Association 2008; World Bioenergy Association 2013), there is still a limitation to how much anaerobic digestion and related biogas and digestate production there could be (Farla, Alkemade, and Suurs 2010). This potential biogas production from anaerobic digestion is smaller than the use of fossil fuels, even if the fullest potential of anaerobic digestion and biogas production could be achieved. It is very hard to make good estimations, but one estimation that has previously been done shows that maybe 
around 3,700 TWh of biogas could be produced from waste materials (excluding forest residues) (World Bioenergy Association 2013), which is far less than the approximate 135,000 TWh of fossil fuels that were used in the world in 2018 (International Energy Agency 2020). In Sweden, it is approximated that 15 TWh of biogas from anaerobic digestion can be produced (Swedish Waste Management Association 2008), which is less than, for example, either the gasoline or the diesel primarily used in cars and heavy vehicles, respectively (Swedish Energy Agency 2020). Renewable methane can also be produced in other ways, such as from gasification of biomass like forest residues (WSP 2013) or from renewable electricity (Parra et al. 2017), which would increase the potential of renewable methane. However, neither of those technologies are used in Sweden at the moment to produce renewable methane. Biogas cannot alone be the solution for substituting all fossil energy, but it can be one essential piece in a larger puzzle of several different solutions that will be needed for substituting the currently used fossil energy (Björner Brauer and Khan 2021). It is, however, not entirely certain where the best place for this puzzle piece will be since biogas can be used in several different areas (Björner Brauer and Khan 2021). Where it is suited to increase, the use of biogas will depend on the context and the other solutions. The other pieces of the puzzle may have characteristics that make them more or less suitable in certain situations. Since biogas will only be one solution among many, parts of the decision about whether or not to use biogas will thus also include considering other alternatives that the decision-maker could use together with biogas or, if the context is such that biogas is not suitable, instead of biogas. In order to reduce the risk of other increased problems, it is also necessary that the decision-makers use a broad viewpoint that includes all of the most important impacts for each alternative.

\subsection{Research questions}

Biogas is primarily used as biomethane for fuels for vehicles in Sweden, and the users of biogas and biomethane are a mix of, for example, consumers, municipalities, haulers, bus operators and manufacturing firms (Ottosson, Magnusson, and Andersson 2020). This thesis focuses on two types of users: private companies (primarily focused on companies that manufacture or sell different kinds of products and require fuel either for transporting goods or for their manufacturing processes) and public organizations (in the form of municipalities and regions). Municipalities in Sweden have to make sure that there are services in the municipality such as water, wastewater treatment, waste management, child care, schools and elderly care (Sveriges Kommuner och Regioner 2021a). Regions, on the other hand, are responsible for health care, dental care and regional development (Sveriges Kommuner och Regioner 2021b). The public transport system is run by the regions together with the municipalities.

Decisions on whether or not to use biogas among such decision-makers can be driven as well as challenged by different factors, which differ between different decision-makers, and the decisions can be difficult due to the complex nature of biogas systems due to, for example, its many actors, the limited nature that ensures that it needs to work together with other solutions and the broad perspective needed to ensure that important aspects are not missed. It has previously been found that guidance for such decisions is needed. Different methods have been developed to support decision-making, such as different tools made sustainability assessments (Ness et al. 2007). However, in a workshop connected to research on public procurement of bus transports in Sweden (Aldenius, Tsaxiri, and Lidestam 2021), it was brought up that there is a need for a broader and longer-term systemic perspective on sustainable bus transport. In another study, several actors that in different ways are connected to biogas in Sweden expressed a need 
to increase the level of knowledge of biogas systems to get an improved understanding among decision-makers in order to be able to make better comparisons with other alternatives (Ammenberg et al. 2018). There is also a general need for improved knowledge and supportive methods to assess the sustainability of different alternatives in decision-making connected to, for example, public procurement (Cheng et al. 2018; Lindfors and Ammenberg 2020).

\section{RQ1: How do biogas systems compare to other potential alternatives?}

Research question 1 (RQ1) focuses on the impacts from biogas systems - considering environmental, social, economic and technical aspects - and how they compare to impacts from other potential alternatives that decision-makers in private companies or public organizations can choose. In many usage areas, different kinds of fossil fuel are used to a large extent - for example, diesel for trucks, gasoline for cars, oil or liquefied petroleum gas for manufacturing industries and marine oil for ships and so forth. Apart from fossil fuels and biogas, there can be other renewable alternatives, such as hydrotreated vegetable oil (HVO), battery electric vehicles and ethanol. Since biogas will likely not be a dominating fuel and instead be one part of a renewable energy puzzle (Björner Brauer and Khan 2021), at least some of those alternatives will also have important roles to play together with biogas. Since biogas systems do not only consist of biogas, the impacts from these systems also include the replacement of mineral fertilizers by the use of digestate as a biofertilizer. Substantial research have previously been done on using biogas and biogas systems and the impacts from that (Hijazi et al. 2016), as well as on technologies that could be seen as alternatives to biogas (e.g. Brynolf, Fridell, and Andersson 2014; Malça, Coelho, and Freire 2014; Osorio-Tejada, Llera-Sastresa, and Scarpellini 2017). The intention with research question 1 is to stimulate a broad analysis of how biogas compares to the other alternatives that the decision-makers could choose to use instead of biogas or in addition to biogas.

\section{RQ2: Why do decision-makers in Sweden find it interesting to use biogas, and what makes them hesitant?}

Research question 2 (RQ2) focuses on the reasonings of decision-makers in private companies and public organizations. Research on the diffusion of environmental technologies has found that there is a number of different factors that might make decision-makers more interested in starting to use a technology that has less negative impacts (e.g. Bergek and Mignon 2017). These can be connected to the actor itself, such as stakeholder requirements, or a higher, societal level like subsidies, national/regional/local goals or existing infrastructure. Previous research has found a number of factors that may act as barriers towards using alternative environmental technologies, such as lack of knowledge, limited financial resources and availability and access to capital (e.g. Mignon and Bergek 2016). Some previous research, such as Ammenberg et al. (2018) and Fallde and Eklund (2015), has focused on the demand side of biogas and what decisions to use or not use biogas were based on. The intention with research question 2 is to expand the findings of previous research by identifying and understanding the reasons for why biogas is a more or less interesting alternative among two types of actors. 


\section{RQ3: How can decision support be used in decision-making to deal with complexities connected to biogas decisions?}

Research question 3 (RQ3) focuses on decision support and how such decision support can be used by private companies or public organizations in their decisions of whether or not to use biogas, especially considering the complexities related to these decisions - such as the number and diversity of the actors involved in biogas systems, the need for biogas to work together with other alternatives and the need for a broad viewpoint to catch all important impacts. There is also an inherent wickedness in decisions connected to sustainability since, for example, it is difficult to formulate exactly what the problems are, and there can be many solutions but none that are completely without problems (Norton 2005). In previous research, decision-makers connected to biogas have expressed a need for increased knowledge (Ammenberg et al. 2018) and a broader systemic perspective on sustainable transport (Aldenius et al. 2021). There is also a general need for improved knowledge and supportive methods connected to sustainability assessments in connection with public procurement processes (Cheng et al. 2018; Lindfors and Ammenberg 2020), and Osorio-Tejada et al. (2017) highlighted the need for assessments for buying freight transport that include a broader sustainability perspective as well as other relevant issues like legislation and availability. The intention with research question 3 is to address how decision support can guide decision-making in this complex area.

\subsection{Scope and limitations}

This thesis explores the underlying reasoning regarding using or not using alternative technologies that have less negative impacts than those primarily used today. It does so by focusing on the context of biogas systems and other renewable fuels in Sweden, and it is thus primarily based on data gathered and studies done in Sweden. The choice of Sweden as the focus is both based on practical reasons, and that it is an interesting case to study. The development of biogas systems in Sweden has been different from most other countries, and there are some specific qualities that make it extra interesting to study. In contrast to most other countries in Europe, Sweden is almost exclusively using waste resources to produce biogas, and biogas systems do not have the legitimacy issues that exist in some countries such as Germany. Instead, biogas systems are something that the Swedish government seems to want to support. That biogas is primarily upgraded to biomethane and used as a vehicle fuel is another contrast to other countries, where biogas is primarily used for electricity and heat production, even if upgrading is increasing in some countries such as Denmark, Finland and France. However, the Swedish setting also sets limitations since experiences and reasoning on new alternative technologies might differ between countries.

The thesis is focused on biogas and biomethane produced from anaerobic digestion. Apart from anaerobic digestion, there is a large forest industry in Sweden and a subsequent large potential to produce renewable methane via gasification of forest biomass and forest residues (Lönnqvist, Grönkvist, and Sandberg 2017). However, this gasification process is not the same as anaerobic digestion and lacks connections to areas like waste management and wastewater treatment, as well as that no digestate is produced that can be used as a biofertilizer. A municipal energy company has built a large-scale demonstration facility for such gasification of forest residues, but even though the technical parts of the facility were functional, it was a commercial failure (Ottosson et al. 2020). Gasification of forest residues and forest biomass is not part of the thesis. It is also possible to produce renewable methane from electricity (Parra et al. 2017). However, 
methane production from renewable electricity also lacks the same connections as anaerobic digestion, and there is no commercial production today in Sweden. It is thus also excluded from the thesis.

There exists considerable research that is specifically focused on decision-making processes, usually focused on either documenting what decision-makers do (aspects of decision-maker behavior) or ways to make a decision (how decision-makers act and whether their actions are liable to be successful) (Nutt 2011). The approach here is different. The focus is on a very specific decision - whether or not to use biogas, and whether to use an alternative instead of biogas or in combination with biogas, and the decision-makers and their decisions are approached from the perspective of sustainable development, systems thinking, sustainability transitions and decision support.

\subsection{Structure of the thesis}

This thesis consists of a cover essay and six appended articles. The cover essay begins with the introduction to the thesis with its context, aims and research questions and how they are approached. Chapter 2, Theoretical background, introduces the concepts and theoretical perspectives that have been used as the foundation for the thesis project for analyzing and discussing the results. Chapter 3, Research methods, presents the methods used in connection with the thesis project and the analysis in the thesis. Chapter 4, Appended papers, gives a short overview of the six appended papers that are part of the thesis. Chapter 5, Actors connected to biogas systems in Sweden, presents an introduction to biogas in Sweden and what actors and decision-makers are involved in decisions that are related to biogas. Chapter 6, Results, presents the results of the appended papers in relation to the thesis and the research questions. Chapter 7, Discussion, discusses and analyzes these results based on the research questions and in relation to other research, as well as discusses the thesis as a whole and presents interesting areas for future research. Chapter 8, Conclusions, provides the final summary of the results of the thesis work. 


\section{Theoretical background}

This chapter presents key concepts and theories central to understanding the context of this thesis, how it connects to different research areas, what perspectives and choices were used and what the frame is for the analysis. Among the concepts and theories that are brought up, sustainable development is the guiding starting point of the research, while the other concepts and theories are more connected to the approach, analysis and discussion of the research and the thesis.

\subsection{Sustainable development}

This thesis starts off from the global sustainability challenges, such as climate change and unsustainable use of terrestrial and aquatic ecosystems, which can be linked to negative impacts on the environment, people or society, and that these are impacts that need to be reduced. For this, it is necessary to encourage a more sustainable development, which according to the most commonly cited definition is "a development that meets the needs of the current generation without compromising the ability of future generations to meet their own needs" (World Commission on Environment and Development 1987). Thus, the world should move towards economic and social progress without negatively impacting the environment (Mensah 2019). In order to accelerate sustainable development, the United Nations launched the 2030 Agenda for Sustainable Development in 2015. It is intended as a "blueprint to achieve a better and more sustainable future for all" (United Nations 2019) and contains a number of Sustainable Development Goals. Anaerobic digestion and the use of biogas and digestate have been shown to contribute positively to several of those sustainable development goals (Hagman and Eklund 2016).

A challenge is that sustainability problems often are wicked problems with difficulties in formulating what exactly the problem is, with no simple or final solution and with no solution that is entirely good or bad (Brown et al. 2010; Rittel and Webber 1973). This can make it hard to make decisions since there will be trade-offs, as well as that it is difficult to consider every aspect that might be impacted. For example, solutions that reduce greenhouse gas emissions might instead lead to increased problems with resource depletion or toxicity (Laurent et al. 2012). It is, thus, important to use systems thinking and avoid too narrow perspectives.

Due to the wickedness of sustainability problems, changing towards a more sustainable world is not easily achieved. Change cannot be achieved by any single actor; instead, sustainable development requires collaborative approaches and actions across many levels, scales and sectors (Fenton and Gustafsson 2017). Research on sustainability problems requires input from various knowledge areas, and collaborative efforts help increasing legitimacy, ownership and accountability for both the problem and the solutions (Mauser et al. 2013). The challenges of sustainability demand that research is integrative and done together with non-academic participants (Mauser et al. 2013).

\subsection{Systems thinking and systems analysis}

Systems thinking is an approach that assumes that there are systems in the world, which are based on different components that interact in order to work towards a common goal (Meadows 2015). Systems thinking uses the concept of systems in order to approach a problem using a broad view that includes all important factors and interactions that are part of and affect the 
presupposed system (Olsson and Sjöstedt 2004). The components can be physical objects, like actual things, infrastructure or natural resources (Hughes 1987). However, systems can also be of a more socio-technical nature and include, for example, actors, organizations and regulations (Hughes 1987). A key part of these systems is that they are interdependent - if a component changes, the other components will change accordingly (Hughes 1987).

Systems and systems thinking are important for this research and this thesis in several different ways. First of all, as explained in the section about sustainable development, there is a need to have a broader consideration than only focusing on one problem at a time. If there is too much focus on, for example, climate change, it is possible that effects related to other issues are missed and that decreases in the emissions of greenhouse gases make other problems worse (Laurent et al. 2012). Such effects are known as suboptimization and problem shifting, respectively (Laurent et al. 2012). There can also be a too narrow viewpoint in relation to products, where relations to other products and other parts of a larger system are omitted, which biogas can give many examples of. For example, if manure is used for biogas production, large reductions of greenhouse gas emissions via reduced methane emissions can be brought compared to current manure handling (Prussi et al. 2020). The resulting digestate has better nutrient availability as fertilizer than manure used directly as a fertilizer (Möller and Müller 2012). However, such impacts will be missed if the viewpoint is limited to the use of biogas as a fuel.

\subsection{Sustainability transitions}

The interdependencies and interactions of large systems mean that no firm or innovation can individually create a large technological change (Carlsson and Stankiewicz 1991), such as a shift towards biogas. The system interactions can thus be a problem if the change is toward an alternative technology that does not entirely fit into the current system (Markard and Truffer 2006). Sustainability transitions is a research area focused on such problems and in which largescale societal changes are studied - "fundamental social, technological, institutional and economic change from one societal regime or dynamic equilibrium to another" (Hölscher, Wittmayer, and Loorbach 2018).

There are different ways to look at the concept of transitions. According to Köhler et al. (2019), there are four main areas in transition research: multi-level perspective (Geels 2002; Rip and Kemp 1998; Smith, Voß, and Grin 2010), strategic niche management (Geels and Raven 2006; Schot and Geels 2008), transition management (Loorbach 2010; Rotmans, Kemp, and van Asselt 2001) and technological innovation systems (Bergek, Jacobsson, Carlsson, et al. 2008; Hekkert et al. 2007; Markard, Hekkert, and Jacobsson 2015; Negro, Suurs, and Hekkert 2008). The concepts regime (existing rule set and structure of the system) and niches (protected spaces where new innovations can evolve) are central themes in several of these research frameworks.

This thesis is primarily focused on transition management, which focuses on how sustainability transitions are shaped or managed. Transition management is a practice-oriented research field, and previous research in the area has clarified the need for engaging with practitioners in collaborative processes (Loorbach 2010; Rotmans et al. 2001).

The particular focus of the thesis is on decision-makers and what lies behind their decision regarding using or not using biogas. It is not enough that there are decisions on a large-scale 
level with policies and to gain such an acceleration - there also needs to be actors that decide to use the new technology. Users/consumers are important for acceleration in order to favor innovations and expand markets. A decision-maker that has decided to use biogas is not only another user but can also decide on increasing their own use later on. They can also function as advocates and help make biogas more mainstream and legitimizing it to other decision-makers (Bergek, Jacobsson, and Sandén 2008; Hillman and Sandén 2008).

Loorbach (2010) has developed a framework for managing transitions based on four steps (not necessarily linear steps): strategic, tactical, operational and reflexive. The strategic step includes structuring and envisioning the problem so that there is a joint vision of the desired direction. In the tactical step, the focus is on how this desired direction can be reached - what barriers there are to the development and how they can be surpassed. The operational step is when actions are carried out to reach the desired direction, and the reflexive step is when the process is monitored and evaluated.

As previously explained, managing transitions and governing for a sustainable development requires that actions (and thus decisions) are taken at many different levels, not only on national and international levels (Fenton and Gustafsson 2017; Köhler et al. 2019). In the context of this thesis, there needs to be a decision made for each new user that has decided on using biogas (or instead decided on using an alternative). Even if that decision is on a very small scale in comparison to the decisions on a national or international level, they are still important both for the decision-maker, since it can be a large and important decision within the company or organization, and for the transition, since a large change is built upon many, many smaller changes.

\subsection{Decision support}

Decisions connected to biogas use can be complex for several reasons. Biogas and other solutions that are meant to deal with sustainability challenges have an underlying wickedness in that there are no exact formulations of what the problems are and that there is no alternative that is completely good and does not cause any problem in any way. It can thus be difficult to make decisions related to sustainability since it is difficult to know what decision is the best in a given situation. Decisions related to biogas are also complex for other reasons, such as the number and diversity of the actors involved in biogas systems, the need for biogas to work together with other alternatives and the need for a broad viewpoint to catch all important impacts.

Previous research has highlighted a need for easily comprehensible guidance in connection to, for instance, purchasing or procurement (Cheng et al. 2018; Guenther et al. 2013; Testa et al. 2016). In order to ease decision-making, different decision support tools have been developed, such as sustainability assessment methods (Ness et al. 2007). Sustainability assessment methods are supposed to support decision-makers in making their decisions by assisting the decisionmakers in evaluating what effects different actions have (Ness et al. 2007). Sustainability assessment methods have developed rapidly in recent decades, with a number of different methods having evolved to ease different kinds of decision-making - there are ways to assess products, countries, material flows, building plans and so forth (Ness et al. 2007). Among the more common ones are, for example, life cycle assessment, which evaluates the environmental impacts of a product throughout its life cycle (Ness et al. 2007), cost-benefit analysis, which 
weights different costs (for example, those associated with environmental impacts) against expected benefits, (e.g. Lajunen 2014; Noel and McCormack 2014; Shirazi, Carr, and Knapp 2015) and multi-criteria analysis (e.g. Osorio-Tejada et al. 2017; Sehatpour, Kazemi, and Sehatpour 2017).

Multi-criteria analysis is a method that is used to identify the best choice considering the circumstances when there are trade-offs between different evaluation criteria (Ness et al. 2007), and there are opinions that it is better for environmental decision-making than, for example, cost-benefit analysis, which can be inadequate for capturing the full range of impacts (Browne and Ryan 2011). Both qualitative and quantitative criteria can be incorporated into the assessment (Beria, Maltese, and Mariotti 2012; Ness et al. 2007).

Another method for decision support, which is common for assessing transition paths (e.g. Azar and Lindgren 2003), is using scenarios to outline and analyze potential futures (Bunn and Salo 1993). For transition-oriented decision-making, the scenario approach (socio-technical scenarios) is more qualitative and focuses on both technology and society (Hillman and Sandén 2008) rather than the stricter traditional scenario methods that are often quantitative and technology-focused (Hofman, Elzen, and Geels 2004). Socio-technical scenarios also have the potential to include storylines to describe the scenarios and relate them to the context (WeimerJehle et al. 2016), as well as explain development processes rather than just final outcomes (Hillman and Sandén 2008). 


\section{Research methods}

This chapter starts by presenting my research journey and how this research came about. It continues by presenting how the thesis was conceived, the research approaches and methods in the thesis project, the different studies involved and some reflections on the research quality. For more detailed information about the methods used in different studies, see the appended papers.

\subsection{Research journey}

My research journey has two beginnings, with one of them being when I, five years ago, began my actual research as a $\mathrm{PhD}$ student at the division of Environmental Technology and Management at Linköping University. However, the other dates further back - namely 13 years ago, when I started high school. Instead of choosing the more common natural or social science programs, or the technical program for that matter, I choose to study a program focused on "international sustainable development". At the time, I only had very vague ideas of what it actually meant, and I could not connect the dots of how the different parts of the education fitted together - with everything from studies in natural and social sciences, to study visits abroad and courses like "environmental politics". I only knew that I found it interesting and wanted to continue on that track, which I did. After finishing high school, I went on to start my university studies in Environmental Engineering. Five years later, filled with courses like "environmental management", "life cycle analysis" and "energy and environmental physics", I was still convinced that this was something I wanted to continue with. I did not really know what form the continuation would be in, but when I looked through job ads, I found an ad about a $\mathrm{PhD}$ student position at Linköping University. At that time, my knowledge of what being a $\mathrm{PhD}$ student meant was still fuzzy, but the research description - studying scenarios for implementing electric buses and alternative uses for biogas - sounded really interesting, especially since I had just finished writing my master's thesis about how municipalities could decrease their use of fossil fuels in transports. And so, I applied for and got the position, and my research journey really started.

My first years as a PhD student were financed by a research project called "The Environmental Bus", funded by Vinnova. It was a collaborative project with the public transport authority, the local municipality and the local utility company, and it was made up of three sub-studies: previous experiences of electric buses in cities, the potential for having electric city buses in the city of Linköping in Sweden and how the leftover biomethane, that would have been used in the city buses if they would not be electrified, could be used instead of in the city buses. My part in the project, which became the first part of my research journey in Linköping, was primarily in the sub-study focusing on alternative uses for biomethane. The research involved literature studies focusing on how biogas is used today and theoretical potential uses, as well as an interview study among different sectors that could use biogas but are not large users, in order to find out what they conceived to be the drivers and barriers for biogas use. In the later stages of the project, during my second and third year as a $\mathrm{PhD}$ student, I was also part of finalizing the project by using the previous sub-studies together with workshops to create scenarios for how electric buses could be implemented while shifting the use of biogas to other purposes. The outcomes of this project are presented in three scientific articles, all of them appended in this thesis: Paper I and Paper II from the sub-study about how biogas can be used alternatively and Paper VI from the finalization of the research project (Table 1). 
However, even if my first years were financed by The Environmental Bus project, my focus on biogas soon made me embroiled in the research on biogas that my colleagues did in connection with the Biogas Research Center. The Biogas Research Center is a national competence center for biogas that is partly financed by the Swedish Energy Agency and partly by more than 20 different partners - ranging from biogas producers, regions, municipalities and biogas distributors to companies working with digestate and international auto manufacturers. During my first years as a PhD student, I was not actually part of the Biogas Research Center, but I still joined the meetings and discussed my and others research. After the Environmental Bus project ended, however, I became more and more part of the Biogas Research Center, especially connected to research there focused on resource-efficient value chains for biogas and on the role of municipalities and regions in developing sustainable biogas solutions. I particularly became part of two projects that were carried out via the Biogas Research Center - one about creating and applying a multi-criteria assessment tool for assessing the sustainability performance of bus technologies and one about business strategies among companies using transport services and their connection to biogas. The outcome of these two projects is presented in three scientific articles: Paper IV and Paper V from the study about multi-criteria assessments for buses and Paper VI from the study about business strategies and biogas.

Apart from The Environmental Bus project and Biogas Research Center, I have also taken part in other projects, courses, and so forth during my years as a $\mathrm{PhD}$ student. One such example was the project "Sustainable Transports in Östergötland", partly funded by the European Regional Development Fund, which focused on how the change to a fossil-independent transport sector could be achieved in the county of Östergötland (see e.g. Anderberg and Dahlgren 2019).

Table 1. An overview of the appended papers' relationships to the projects I worked in.

\begin{tabular}{|c|c|c|c|c|c|c|}
\hline & 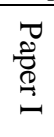 & 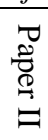 & 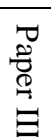 & 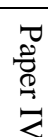 & 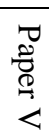 & 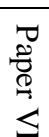 \\
\hline The Environmental Bus project & & & & & & \\
\hline $\begin{array}{l}\text { Biogas Research Center-project about multi-criteria } \\
\text { assessment for bus technologies }\end{array}$ & & & & & & \\
\hline $\begin{array}{l}\text { Biogas Research Center - project about business } \\
\text { strategies among companies and their connection to } \\
\text { biogas }\end{array}$ & & & & & & \\
\hline
\end{tabular}

\subsection{The thesis}

In adherence to the traditions of the division of Environmental Technology and Management, this is a compilation thesis built up of a cover essay and six appended papers. The approach of developing the cover essay, which is intended as a synthesis of the appended papers, was similar to that of thematic analysis. Thematic analysis is usually used for analyzing interviews and is performed by searching for themes and common recurring motives in interviews (Bryman 2015). Instead of using it in interviews, I searched for connections and themes in the appended 
papers based on the aim and the research questions of the thesis. Table 2 provides an overview of which research questions that each appended paper relates to.

Table 2. An overview of the appended papers' relationships to the research questions. Grey boxes indicate that the findings of the paper are used to answer the research question.

\begin{tabular}{|c|c|c|c|c|c|c|}
\hline & 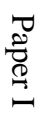 & 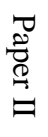 & 苞 & 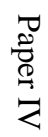 & 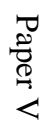 & 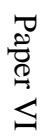 \\
\hline $\begin{array}{l}\text { RQ1: How do biogas compare to other potential } \\
\text { alternatives? }\end{array}$ & & & & & & \\
\hline $\begin{array}{l}\text { RQ2: Why do decision-makers in Sweden find it } \\
\text { interesting to use biogas, and what makes them } \\
\text { hesitant? }\end{array}$ & & & & & & \\
\hline $\begin{array}{l}\text { RQ3: How can decision support be used in decision- } \\
\text { making to deal with complexities connected to biogas } \\
\text { decisions? }\end{array}$ & & & & & & \\
\hline
\end{tabular}

\subsection{Research approaches}

Two approaches have been central in the whole thesis project - systems analysis and integrated and participatory research.

\subsubsection{Systems analysis}

Systems thinking and systems analysis have been integral to the research connected to the thesis. Biogas systems are complex systems, given anaerobic digestion, the production and use of biogas and digestate and the many actors and sectors included to make it all function. This research has focused not only on the use of biogas but also on how the substrate or digestate affects local/regional environmental impacts or what different actors are needed to work together to increase biogas use. Relevant impacts do not only include greenhouse gases from combustion processes, but are also related to different production stages and by-products and may also include different environmental impacts and other impacts such as impacts on nutrient recirculation or energy security. If the analysis is too narrow and only focuses on the use of the biogas, large parts of the impacts will be missed. This can be shown in, for example, Paper V, where in order to fully assess different alternative technologies for buses, the analysis had to include, for instance, how the production of fossil fuels impacts the ecosystems and how byproducts from ethanol production can be used as animal fodder which could be used instead of soy protein. The focus is thus not only on the bus but also on how the related technical systems affect society.

\subsubsection{Integrated and participatory research}

Integrated and participatory approaches have also been an important part of the research.

Inter- and transdisciplinarity are important parts of research on sustainability (Stock and Burton 2011). Sustainability research often stems from a societal need to deal with complex problems, and dealing with such problems most often requires less traditional methods of doing research, 
such as combining several different research areas (Mauser et al. 2013). More integrated research, where the lines of traditional research areas and disciplinary boundaries are blurred, is also claimed to be an important part of transitions research (Köhler et al. 2019). All the research connected to the appended papers has moved across traditional disciplines and research areas and built on combining different knowledge areas and research methods. The focus is not only related to research on environmental issues but also on social issues and economic and technical ones, and knowledge and methodological inspiration have been fetched from different research fields. Since Paper IV and Paper V focused on catching as broad viewpoint as possible, we organized an extra review process with researchers in various related fields to ensure that the viewpoint was not too narrow.

Participatory research has also been important in this research. A good collaboration between researchers and non-academic stakeholders can increase both the legitimacy and accountability for the problem and the potential solutions (Mauser et al. 2013). Mauser et al. (2013) state that the results of sustainability research should be able to help stakeholders make informed decisions. The studies of Papers IV, V and VI were all built on stakeholder involvement through workshops or other means. Participatory approaches have also been found to be important for research on how transitions should be managed (Köhler et al. 2019). Papers IV, V and VI all involved stakeholders, either through workshops or other collaborative means.

Paper IV and V are both focused on assessments of different bus alternatives for public organizations who procure buses for public transport. Participation of public organizations were extremely important for this project, since they could contribute with the subjective opinions of public organizations on what aspects are important for them in similar decisions. The participatory method of workshops thus allowed us to better understand the kind of actor that the assessment was aimed at and what lies behind that kind of actor's decisions. Other actors were also involved, but more as experts on their areas in order to enable a good assessment of all the alternatives in all the indicators. Regarding paper VI, it focused on exploring scenarios for electrifying buses and using biogas in different ways. Participatory methods were very important for that project as well. The actors that would be involved in the changes required for the scenarios gave us a better understanding of what changes could be achieved by them and what would be required. Apart from that, opinions from experts in different relevant areas allowed us a broader view of the scenarios, what would happen if they were achieved and how they could be achieved.

However, participatory research does have its challenges. There will always be limits for the number of participants and their degree of participation and the results may differ due to the particular mix of participants and how they are involved. The results might not differ much, but there will likely be some differences with a different group of people, which must be considered in the research. For Paper VI, it was primarily the participatory process that was important with meetings, workshops, discussions on how different futures could be reached and so forth. The final results on, for example, exactly how much greenhouse gas emissions would be reduced for a certain scenario was not as important. The importance of the participatory process was also clearly shown in the project, as the process helped increase the legitimization of the scenarios during the project - some of the participating stakeholders during the project slowly changed their views on whether or not electric buses could be a legitimate alternative for Linköping. For Papers IV and V, the process was important in that the process of how the 
assessment method was created, with participation from relevant stakeholders, can be used in other areas as well. However, the results of the participatory process were also very important, as they were meant to help municipalities, regions and similar to understand how they can assess bus solutions using different criteria, what criteria can be important for bus solutions and a general overview of how common bus alternatives can be assessed. Since the results were important, even though participatory processes results in subjective results that would differ with a different mix of stakeholders involved, it was considered important to involve several different actors to confirm that the results were fitting. How the results can be used and how they might change in other circumstances are further discussed in Papers IV and V.

\subsection{Overview of used methods}

Three main methods were used for data collection in connection with the research: literature and document reviews, interviews and workshops. Table 3 provides an overview of which of these three methods were used in the appended papers.

Table 3. An overview of the methods that were used in the research, based on the appended Papers I-VI.

\begin{tabular}{|l|l|l|l|l|l|l|}
\hline & Paper I & Paper II & Paper III & Paper IV & Paper V & Paper VI \\
\hline $\begin{array}{l}\text { Literature and } \\
\text { document reviews }\end{array}$ & & & & & & \\
\hline Interviews & & & & & & \\
\hline Workshops & & & & & & \\
\hline
\end{tabular}

\subsubsection{Literature and document reviews}

Reviews of literature and documents have been done continuously during the entire research process, with some extra intensive periods focusing on particular areas. The reviews have particularly focused on academic literature in the form of peer-reviewed journal articles and reports produced by government agencies and other organizations that are neither commercial nor academic, so-called gray literature. In connection with Paper I, the review also consisted of articles in newspapers, magazines and periodicals that were an important source of information. These reviews were carried out either by me, the other authors of the papers or the other project participants. Table 4 provides an overview of the literature and document reviews in connection with the appended papers. 
Table 4. The literature and document reviews connected to the different papers. Italics indicate that I only had a limited part of that review.

\begin{tabular}{|l|l|l|}
\hline \multicolumn{2}{|l|}{ Literature and document reviews } \\
\hline Paper I & - & $\begin{array}{l}\text { Review of journal articles, gray literature and mass media for an } \\
\text { overview of alternative biogas-based fuels }\end{array}$ \\
\hline Paper II & - & $\begin{array}{l}\text { Review of journal articles on drivers and barriers for technological } \\
\text { choice in industry }\end{array}$ \\
\hline Paper III & - & $\begin{array}{l}\text { Review of journal articles focusing on freight transport, renewable } \\
\text { fuels, transport buyers and transport providers }\end{array}$ \\
\hline Paper IV & - & $\begin{array}{l}\text { Review of journal articles on sustainable public procurements and } \\
\text { sustainability assessments }\end{array}$ \\
& - & $\begin{array}{l}\text { Review of journal articles and gray literature on indicators and scales } \\
\text { that could be relevant for assessing bus technologies }\end{array}$ \\
\hline Paper V & - & $\begin{array}{l}\text { Review of journal articles and gray literature on how alternative bus } \\
\text { technologies (including biomethane) are assessed according to the } \\
\text { indicators and scales established in Paper IV }\end{array}$ \\
\hline Paper VI & - & $\begin{array}{l}\text { Review of journal articles on scenario construction and evaluation } \\
\text { Review of, for example, gray literature on the current regional } \\
\text { transport demand and other case-specific data }\end{array}$ \\
\hline
\end{tabular}

In some of the papers, the collection of statistics was important. In the case of the review for Paper I, international and Swedish statistical reports were preferred as source material since the data is likely based on all the available and updated statistical data. National and regional statistics and reports were also important for Paper VI in order to understand the regional transport development in the county of Östergötland, Sweden. Outputs from different types of mass media were used in Paper I for technologies that were not part of national statistics, and in order to show that these technologies are technically feasible even if they are not yet used to any larger degree. In most cases, these articles and news releases were of the type that "company $\mathrm{X}$ has changed/is going to change to technology $\mathrm{Y}$ that is better", which portrayed the companies involved very positively. However, although the media outputs of this type are biased, they do show that it is actually possible to use Technology Y in the sector of Company $\mathrm{X}$. It also shows the technology is not common and widespread; otherwise, it would not have been news materials. Regarding the reviews for Papers IV and V, it was important to find quality data regarding possible indicators, scales and how the alternative bus technologies could be assessed. 


\subsubsection{Interviews}

Interviews have been part of the research connected to Papers I, II, III and VI (Table 5).

Table 5. An overview of the interviews done in connection to the different papers.

\begin{tabular}{|l|l|}
\hline \multicolumn{2}{|l|}{ Interviews } \\
\hline Paper I & Interviews with transport manufacturers regarding different biogas-based fuels \\
\hline Paper II & $\begin{array}{l}\text { Interviews with representatives of companies connected to heavy transport, } \\
\text { manufacturing and shipping about what they experience as drivers and barriers } \\
\text { towards biogas use }\end{array}$ \\
\hline Paper III & $\begin{array}{l}\text { Interviews with representatives of companies that use heavy road transports to } \\
\text { transport their products about how they work with sustainability and transports } \\
\text { and how they look at biogas and other renewable fuels }\end{array}$ \\
\hline Paper IV & \\
\hline Paper V & \multicolumn{2}{|l}{} \\
\hline Paper VI & Interviews about case-specific data \\
\hline
\end{tabular}

In connection with Papers I and VI, interviews were only a limited part of the data collection. They were mostly done as a complement to support and confirm the analysis and the outcomes of the literature and document studies and the workshops. In connection with Paper I, the interviews were predominantly introductory to gain knowledge of the studied areas, while the interviews in relation to Paper VI focused on particular issues that the interviewees were considered to be knowledgeable in.

For Papers II and III, interviews were the primary data collection method, and the papers are mostly based on those interviews. These interviews in Paper II and Paper III were performed in a similar fashion, with semi-structured interviews using an interview guide but with possibilities to add questions depending on the interviewee's answers. The majority of the interviews took place either by telephone or video chat, which according to Bryman (2015) has little difference to in-person interviews regarding the response the researcher gets. All interviews were recorded and fully transcribed to allow for thorough and repeated examination and bring the other project participants and me closer to each participant's response, in accordance with Bryman's (2015) suggestions regarding interviews. Having more participants in the interviews could have enriched the analysis and results as more viewpoints would have been included. However, finding relevant companies that agreed to be interviewed proved very difficult and timeconsuming in relation to both these interview rounds.

Paper II focused on drivers and barriers for biogas usage in three sectors where biogas is not currently used that much: manufacturing, road transport and shipping. In order to find what drivers and barriers exist in these sectors, interviews were done with private companies connected to each sector that either were using biogas, were going to start using biogas or had decided to use other renewable alternatives instead of biogas. In total, 11 different companies were interviewed - four manufacturing industries, three companies that have large amounts of road transports and four companies connected to shipping. 
Paper III focused on freight transport-related environmental considerations by interviewing 11 different private companies in different sectors that are working with sustainability in some way and that buy heavy road transport services or have their own trucks.

Each company chose who in the company should do the interview after having been informed of the focus areas of the interview - or whether several of the company's employees should be part of the interview. The companies interviewed for both Paper II and Paper III are a mix of Swedish companies, international companies with their main base in Sweden, international companies originating from Sweden, and international companies with part of their work in Sweden. For the international companies, the focus was primarily on their sustainability work within the part of the company that is active in Sweden.

These interviews were then analyzed according to the principles of thematic analyses. According to Bryman (2015), thematic analysis can involve activities searching for themes by finding recurring motives through a thorough reading of transcripts and producing themes from these motives. Accordingly, the interviews connected to Papers II and III were analyzed by seeking patterns in the interview responses and identifying factors that the interviewees expressed as important.

The interviews are used to observe why the decision-makers find biogas interesting or what makes them hesitant. The number of respondents of both private companies and public organizations was too low to draw any definite statistical conclusions, and the results were primarily used for qualitative analysis. From the analysis of the interviews, it is possible to state that the reasonings exist among private companies and public organizations, but it is not possible to give good quantitative approximations of how common the reasonings were.

\subsubsection{Workshops}

This thesis is also based on the concepts of integrative and participatory research. As such, collaborations with actors outside academia, in order to better suit the research to the actual needs of society and to provide knowledge of their expert areas, have been an important part of several of the research projects in the form of workshops. Workshops were part of the projects connected to Papers IV, V and VI (Table 6).

Table 6. An overview of the workshops done in connection to the different papers.

\begin{tabular}{|c|c|}
\hline \multicolumn{2}{|c|}{ Workshops } \\
\hline Paper I & \\
\hline Paper II & \\
\hline Paper III & \\
\hline Paper IV & - Several different kinds of workshops with a diversity of actors \\
\hline Paper V & - Several different kinds of workshops with a diversity of actors \\
\hline Paper VI & $\begin{array}{l}\text { - Several meetings with representatives from local partners } \\
\text { - } \quad \text { A workshop involving participants from twelve different organizations }\end{array}$ \\
\hline
\end{tabular}


The project that Paper VI is connected to, "the Environmental Bus" project, was a collaborative one involving three local actors as partners, who were represented at regular project meetings and were in the beginning part of framing the project. At times, other relevant actors were also part of those meetings. Apart from those meetings, a workshop was held with 24 participants from 12 different organizations to establish potential scenarios for implementing electric buses. The participants were sent background material to read beforehand, and at the workshop, they were divided into three groups: one discussing a baseline scenario, one examining the smallscale implementation of electric buses and one considering large-scale implementation of electric buses. The groups discussed issues like how the scenarios could be realized and what the results would be.

The project within the Biogas Research Center that was the basis for Papers IV and V featured regular workshops at the beginning of the project with the local public authority and a large biogas producer and distributor, at which the various criteria were developed iteratively. Apart from these workshops, potential indicators, scales and results were also presented and discussed with different members of the Biogas Research Center during additional dedicated workshops, research area meetings, presentation/discussion sessions and poster presentations.

Each participant in these meetings and workshops can be considered subjective and think mainly from the perspective of the organization they represented. However, such subjective responses are what we wanted to gain from the workshops - insights into the participants' subjective thoughts on different matters. Having more participants might have included more knowledge and other viewpoints that could have improved the work, but all work with different actors is time-consuming and difficult to manage so that participants will attend, especially with a large number of participants. It was thus important to balance having enough participants to get sufficient value out of the meetings and ensuring that there were not so many participants that it would be difficult to schedule it.

\subsection{Reflections on the research quality}

Lincoln and Guba (1985) have been major influences regarding qualitative research quality, and they have suggested different criteria for judging the quality of research depending on what the basic beliefs are (Guba and Lincoln 1994). Four criteria are suggested for if the belief is that there exists an indisputable reality that research is trying to understand, even if humans might never understand the reality perfectly (positivism and postpositivism): internal validity (that the findings correspond to reality), external validity (generalizability), reliability (that the results are stable) and objectivity (that the observer is distanced and neutral). If the basic belief instead is that reality can be understood as a number of mental constructions that can be changed, Lincoln and Guba (1994) suggest two other sets of criteria: trustworthiness, which includes credibility, transferability, dependability and confirmability (similar to the previously mentioned internal validity, external validity, reliability and objectivity), and authenticity (which includes that the research should be fair, stimulate action, empower action, lead to improved understanding etc.).

Based on the research by Lincoln and Guba, Korstjens and Moser (2018) guide that there are five criteria in particular that are important for qualitative research: credibility, transferability, dependability, confirmability and reflexivity. Reflexivity is explained by Korstjens and Moser as "the process of critical self-reflection about oneself as researcher and the research 
relationship". Tracy (2010) presented another model for quality in qualitative research, with eight criteria: worthy topic, rich rigor, sincerity, credibility, resonance, significant contribution, ethical and meaningful coherence. In a survey study about quantitative and qualitative research, Bryman et al. (2008) found that validity and credibility were regarded as the most important criteria for qualitative research and that reliability and confirmability were also quite important. However, replicability, generalizability, transferability and dependability were seen as less relevant. The responding researchers also mentioned other important criteria for qualitative research: explicitness and transparency, relevance to and involvement of users, and reflexivity. Generally, the respondents preferred a combination of traditional and alternative criteria.

The following reflection on the research quality is based on Lincoln and Guba's concept of trustworthiness and thus focuses on credibility and confirmability along with dependability and transferability. However, the reflection also draws inspiration from other sources.

\subsubsection{Credibility}

The credibility criterion focuses on how believable the findings are (Bryman et al. 2008). Tracy (2010) explains that the research should be marked by for example triangulation, concrete details and thick descriptions, multivocality and member checks (i.e. feeding data back to the group from whom the data was originally obtained (Korstjens and Moser 2018)). Triangulation can be both data triangulation, that is, using multiple data sources, and investigator triangulation, or in other words using more than one researcher to make coding, analysis and interpretation (Korstjens and Moser 2018). In this research, primarily data triangulation, investigator triangulation and member checks were used as strategies to ensure credibility. All of the papers are partly based on some sort of literature and document review together with either interviews or workshops. This gave the possibility to see similarities and differences between different sources. In connection with the literature and document reviews, there was an effort to find several sources discussing the same matters. This made it possible to better understand the results of previous studies in a certain area and to identify the uncertainty span of diverging results (e.g., Paper V). In parts of the research, I worked together with other researchers on the same part of a study. In connection to the interview studies, manuscripts or transcripts were sent out to the interviewees to ensure that we understood them correctly in the interviews.

\subsubsection{Confirmability}

The confirmability criterion focuses on that the observer should be distanced and neutral (Guba and Lincoln 1994) and that the results should be able to be confirmed by other researchers to ensure that the findings are based on actual findings and not on the researcher's imagination (Korstjens and Moser 2018). Together with the other authors of the appended papers, I have tried to transparently describe how the research was done and what data we have based the findings on. In Papers IV and V, transparency was one of the major drivers in the developing and applying the multi-criteria assessment method. We tried to ensure that all assumptions were clearly described and that the data used were referenced to their original sources. At the end of Paper V, a table is presented that includes all the results for all of the alternatives and indicators, as well as how certain we were of the results. Regarding interviews and workshops, it is, unfortunately, more difficult to be completely transparent. For example, the interviewees in 
Paper III asked to be anonymous, which means that the details of the interviews and the transcripts cannot be shared and thus cannot be confirmed by others.

\subsubsection{Transferability}

The transferability criterion focuses on whether the results can be generalized (Guba and Lincoln 1994) or applied to other contexts (Korstjens and Moser 2018). This thesis and the appended papers are studying a specific national (Sweden) or regional (Östergötland, Sweden) context. Compared to other countries, the Swedish case has both similarities and dissimilarities.. Among the most important differences to other European countries is that Sweden has biogas subsidies connected to the use rather than the production. Biogas has also to a larger share been used as a vehicle fuel in Sweden, but this is changing in several countries with increasing interest in upgrading the biogas to biomethane and using it in vehicles. Regarding the multicriteria assessment in Papers IV and V, the focus was on Sweden but it was also discussed how the method and the results would be similar or different to other geographical areas. The overall discussion in those papers on the need for decision-support and the possible reasons behind decisions is likely to be of general relevance, even if some of the details would require adjustments to fit into another particular context.

\subsubsection{Dependability}

The dependability criterion focuses on that the research should be reliable and stable (Guba and Lincoln 1994) and that the findings would be similar if the study was repeated in the same context, with the same methods and the same participants (Shenton 2004). Strategies to achieve this are, for example, using overlapping methods or having in-depth methodological descriptions that allow the study to be repeated (Shenton 2004). As previously mentioned, the other authors and I have tried to describe the methodology in-depth in the appended articles. However, using interviews and workshops as methods makes it harder to repeat the studies exactly. The interviews were semi-structured, and only the basic structure of the questions is mentioned in the method descriptions in the paper. The flexible and unstructured part of the interviews would thus be difficult to replicate. There is a similar difficulty with workshops. Even if the same persons were gathered with the same questions, it is in human nature that the discussion would be at least slightly different. The anonymity of the interviewees in Paper III unfortunately also makes it impossible for another researcher to repeat the study, since it would not be possible to obtain the same participants. Overlapping methods are only used very briefly in the case of buses and other vehicles using biogas as fuel and their impacts and possibilities, with literature reviews, interviews and workshops done on similar areas.

An inherent challenge with dependability in this research, however, is that if any time has passed between the study and a repeat of the study, there will be an effect on the findings. All of the papers show the results gained at a particular point in time. The results of repeated similar studies in the future can not possibly be done in exactly the same context as an older study since the context will have changed during that time with various future developments. Such changes can, for example, be those in the transport situation, technical maturity, costs or in how biogas is viewed by different companies. Some of the results would, however, likely be similar. For example, the findings in Paper II fit well with previous studies of industrial companies' energy choices. 


\section{Appended papers}

This thesis has six appended papers, which are shortly introduced here via summaries of their backgrounds, presentations of some key findings that connect to the thesis and explanations to how I contributed to the papers.

\subsection{Paper 1}

Dahlgren, S. (2020). Biogas-based fuels as renewable energy in the transport sector: an overview of the potential of using CBG, LBG and other vehicle fuels produced from biogas. Biofuels. https://doi.org/10.1080/17597269.2020.1821571

\section{Background and aim}

The energy supply in the world needs to change from fossil fuels to renewable alternatives. Biogas is such a renewable alternative, and there is potential to increase biogas production in the world. Biogas is primarily used for power and heat production, but it can also be used for other purposes, and in recent decades the interest in upgrading biogas to biomethane has increased. In the last few years, the interest has also increased in liquefying biogas for heavier transports. At the same time, biogas can also be a raw material for other fuels by gasifying the biogas, for example, Fischer-Tropsch fuels, methanol, dimethyl ether and hydrogen. Each of these fuels has different characteristics and potentials that make them suitable for different parts of the renewable energy system.

The aim of Paper I was to contribute with an overview and an increased understanding of fuels that can be produced from biogas and their potential to be used as a substitution for fossil energy in the transport sector. This was achieved by answering three research questions: For what purpose have the different fuels been developed? What strengths and weaknesses do these fuels have? And, how far have the fuels come in their development, and how are they produced and used today?

\section{Key findings}

There are two main tracks for fuel production from biogas - upgrading it to biomethane or gasifying it to syngas and then using the syngas for further fuel synthesis. The upgraded biomethane can be either compressed (CBG) or liquified (LBG). The syngas can be used to produce, for example, hydrogen, methanol, dimethyl ether or Fischer Tropsch diesel. Some of the fuels produced from syngas have properties that CBG or LBG lack, such as being possible to use in fuel cell vehicles without combustion engines, being compatible in a large share of the existing vehicle fleet or being liquid at room temperature. All of these fuels are used on a large scale today worldwide (although not necessarily for vehicles). However, they are primarily produces using fossil resources. CBG and LBG are the only two options using biogas to produce it commercially in more than a handful of production locations worldwide.

There are millions of vehicles and thousands of refilling stations in the world that are compatible with compressed methane, such as CBG. There are a number of auto manufacturers that produce vehicles that can run on compressed methane, and these vehicles are a mix of, for example, small city cars, SUVs and light commercial vans. However, compressed methane is best suited for smaller-sized vehicles or heavy vehicles that only drive short distances since it requires large volumes to transport the gas. $\mathrm{LBG}$ requires less storage volume than $\mathrm{CBG}$, which 
makes it a better choice for heavier road transports. There is also an interest in liquefied methane in the shipping industry, primarily due to air pollution regulations. There are over a hundred thousand trucks using liquefied methane in China alone, and several of the large auto manufacturers that produce trucks have some versions that can run on liquefied methane. However, although the refueling infrastructure in Europe is increasing, it is still limited, and there are much fewer plants that produce liquefied biomethane than compressed biomethane.

A difficulty with producing fuel from biogas is that the raw materials of biogas are spread out with smaller volumes over a larger area, which might limit the scale of production plants. CBG can be economically feasible at smaller volumes, but LBG production plants often require at least $50 \mathrm{GWh}$ of yearly production to be economically feasible. In Sweden, over $90 \%$ of the biogas production plants produce less than $20 \mathrm{GWh}$. The production scale can also be a difficulty for biomethane use in shipping since ships can require large amounts of fuel. As an example, one of the ships using fossil liquefied methane in Sweden uses twice as much fuel as the yearly production of the largest biogas plant in Sweden.

\section{My contribution}

I carried out the study and wrote the paper, with continuous support and supervision from Stefan Anderberg regarding, for example, framing, scope, and wording.

\subsection{Paper II}

Dahlgren, S., Kanda, W., \& Anderberg, S. (2019). Drivers for and barriers to biogas use in manufacturing, road transport and shipping: a demand-side perspective. Biofuels. https://doi.org/10.1080/17597269.2019.1657661

\section{Background and aim}

Contemporary environmental problems require a transition to renewable energy. Biogas is one alternative, which besides being renewable, has many other benefits. For further expansion of biogas production, it seems necessary to develop new areas of biogas usage where biogas can replace fossil fuels. Industrial gas users, road transport and shipping have been suggested as potentially important biogas users in the future. Paper II addressed the prospects for expanding biogas usage in those three sectors, which up to now have been marginal usage areas in Sweden. The aim of Paper II was to contribute to the current discourse on increasing the share of energy from renewable energy sources in different sectors. This was achieved by answering two research questions: What are the major drivers and barriers for increased biogas usage in the road transport, manufacturing sectors and shipping? And, in which settings can biogas already be a feasible option and what is needed for wider introduction and use in other settings?

\section{Key findings}

Table 7 presents a summary of the drivers and barriers that were identified. Common drivers for actors within all three sectors (manufacturing, road transport and shipping) were that environmental actions were important for the companies and that the companies could take market shares by being "the environmental option". Common barriers were either related to cost (too expensive or unfavorable policies) or the biogas itself (too little production, not suitable/compatible or a lack of infrastructure). 
Table 7. The drivers and barriers experienced by the companies in the studied sectors.

\begin{tabular}{|c|c|c|c|}
\hline & Manufacturing & Road transport & Shipping \\
\hline Drivers & 4 companies & 3 companies & 4 companies \\
\hline $\begin{array}{l}\text { Environmental actions are important } \\
\text { for the company }\end{array}$ & $\begin{array}{l}\text { Agroetanol } \\
\text { Arvid Nordquist } \\
\text { Svenska brasserier } \\
\text { Toyota Material Handling }\end{array}$ & $\begin{array}{l}\text { Arla Foods } \\
\text { IKEA } \\
\text { Svenska retursystem }\end{array}$ & $\begin{array}{l}\text { Wallenius Marine } \\
\text { Stena Line }\end{array}$ \\
\hline $\begin{array}{l}\text { Taking market shares by being 'the } \\
\text { environmental alternative' }\end{array}$ & $\begin{array}{l}\text { Agroetanol } \\
\text { Arvid Nordquist } \\
\text { Svenska brasserier }\end{array}$ & $\begin{array}{l}\text { Arla Foods } \\
\text { IKEA } \\
\text { Svenska retursystem }\end{array}$ & $\begin{array}{l}\text { Thunbolagen } \\
\text { Stena Line }\end{array}$ \\
\hline Family business & $\begin{array}{l}\text { Arvid Nordquist } \\
\text { Svenska brasserier }\end{array}$ & - & Wallenius Marine \\
\hline Contract requirements & - & - & Styrsöbolaget \\
\hline $\begin{array}{l}\text { Internal biogas production } \\
\text { Barriers }\end{array}$ & Agroetanol & - & - \\
\hline $\begin{array}{l}\text { The unreliability and short- } \\
\text { sightedness of the } \\
\text { current policies }\end{array}$ & Arvid Nordquist & $\begin{array}{l}\text { Arla Foods } \\
\text { Svenska retursystem }\end{array}$ & - \\
\hline Policies reward other fuels more & Toyota Material Handling & & $\begin{array}{l}\text { Stena Line } \\
\quad \text { Wallenius Marine }\end{array}$ \\
\hline Biogas is expensive & Svenska brasserier & - & $\begin{array}{l}\text { Stena Line } \\
\text { Thunbolagen } \\
\text { Wallenius Marine }\end{array}$ \\
\hline Lack of suitable biogas & Toyota Material Handling (liquefied) & $\begin{array}{l}\text { Arla Foods } \\
\text { IKEA }\end{array}$ & $\begin{array}{l}\text { Stena Line } \\
\text { Thunbolagen } \\
\text { Wallenius Marine }\end{array}$ \\
\hline Lack of infrastructure & $\begin{array}{l}\text { Arvid Nordquist } \\
\text { Svenska brasserier }\end{array}$ & - & - \\
\hline Not compatible with current system & $\begin{array}{l}\text { Agroetanol } \\
\text { Toyota Material Handling }\end{array}$ & $\begin{array}{l}\text { Arla Foods } \\
\text { Svenska retursystem }\end{array}$ & $\begin{array}{l}\text { Stena Line } \\
\quad \text { Wallenius Marine }\end{array}$ \\
\hline $\begin{array}{l}\text { Existing biogas technology is } \\
\text { not suitable }\end{array}$ & - & Svenska retursystem & $\begin{array}{l}\text { Styrsöbolaget } \\
\text { Thunbolagen }\end{array}$ \\
\hline Contract requirements & - & - & Styrsöbolaget \\
\hline $\begin{array}{l}\text { Previous bad experience with } \\
\text { methane gas }\end{array}$ & - & Arla Foods & - \\
\hline
\end{tabular}

The findings from the interviews confirmed some of the drivers and barriers identified in previous literature, such as branding, lack of physical infrastructure and limited financial resources. Both system-level and actor-level drivers were of importance. Other previously identified drivers and barriers were not mentioned in the interviews, such as lack of knowledge or improving social status. Intergenerational thinking in a family business was one driver that was not often mentioned in previous literature on renewable energy adoption. Among the interviewed companies, two had already changed to start using biogas - and both of them stressed that intergenerational thinking was important for them.

The different drivers and barriers interact through synergies and sometimes conflicts. For example, contract requirements in public procurement processes can be either barriers or drivers, depending on the circumstances. The supplier must meet the environmental requirements specified in the procurement but has no incentives for additional actions. Contract requirements for biogas in buses can force buses to use biogas, but this might decrease the amount of biogas reaching the market and be a barrier for other companies potentially interested in biogas.

The study found that there are some drivers and barriers that are specific to different sectors. In shipping, the fuel costs represent a more significant share of the total operational costs than in the manufacturing and road transport sectors. Lack of infrastructure is particularly connected to the manufacturing sector as the factories are located at specific sites and cannot relocate easily. There should be a careful consideration of the different mixes of barriers and drivers in connection with the development of policies. There are also differences among what drives the adopters, which also needs to be considered in connection with policies to stimulate increased biogas usage. 


\section{My contribution}

This paper was prepared and written in collaboration between the three authors, from idea to submission. However, the authors were responsible for different parts of the paper. My contribution was mainly in connection with sectorial knowledge and the interviews. I wrote the results of the paper and the methods section regarding the interviews alone and co-wrote the discussion in direct collaboration with Wisdom Kanda. All three authors were equally involved in the restructuring and rewriting process after the first submission.

\subsection{Paper $\mid$ II}

Dahlgren, S., Ammenberg, J. Environmental considerations regarding freight transports among Swedish transport buyers. Manuscript

\section{Background and aim}

Freight transports are associated with many environmental challenges. However, freight transports are often overlooked and there have been a low interest in environmental improvements. Transport buyers can be crucial for decreasing their environmental impacts, but there seem to be many question marks regarding what is and can be required. Specific requirements regarding particular vehicles and fuels seem to be not that common. The choice of fuel can, however, be crucial regarding environmental performance. In Sweden, it is possible to use renewable fuels such as biomethane, biodiesel, ethanol and green electricity, but the use of fossil fuels is still significant. The existence of these fuels in parallel makes it interesting to learn about possibilities regarding renewable fuels.

The aim of Paper III was to learn more about transport buyers' environmental considerations regarding freight transports. This was achieved by answering three research questions:

i) Do the transport buyers use any freight transport-related environmental requirements? If so, what kinds of requirements are applied?

ii) What are the reasons behind the requirements/practices, and can these be linked to company environmental strategies and/or the interaction with the transport providers or other stakeholders?

iii) How do the transport buyers look upon the possibility to use renewable fuels? What are their views on different alternatives?

\section{Key findings}

Transport buyers focus primarily on service reliability and costs when choosing freight transport services, and environmental considerations have lower priority. It differed between companies whether they were willing to pay extra for improved environmental sustainability. A large variety of drivers motivated the companies to work with environmental sustainability: stakeholder pressure, branding, resource efficiency, legislative requirements, risk management and so on. Branding was most commonly mentioned. Several of the companies seemed to work with shifting towards more sustainable business models.

The transport providers seemed to be reactive in the relation with the transport buyers, with the transport buyers taking most of the environmental initiatives. Several transport buyers found it 
difficult to influence some transport providers regarding the environmental performance of their freight transports, especially the largest transport providers.

All of the interviewed companies had requirements connected to the environment. These requirements were primarily either that there should be a certain amount of renewable fuels or that the greenhouse gas emissions should decrease, but there were also examples of requirements for specific fuels or technologies. If the transport buyer only had general requirements on greenhouse gas emissions or share of renewables, there was a clear pattern that only the cheapest and easiest alternative was used - HVO or rapeseed methyl ester (RME). Biomethane, and other alternatives that require investments in new vehicles, were only used when there were specific requirements for that particular fuel. However, both biogas and electric vehicles were seen as better long-term options than HVO according to the transportbuyers. The interviewees found biomethane to be one of the best alternatives considering policy climate, recent developments, and long-term potential, while there were many uncertainties regarding $\mathrm{HVO}$ and its availability in the future.

There is also a challenge that contracts can be quite short. Special technologies like biomethane might require longer contracts in order to enable the transport providers to make investments. The interviewees also mentioned challenges specific to biomethane, such as a lack of available LBG, a lack of refueling infrastructure, a lack of interest among the truck producers to sell LBG trucks and that LBG trucks are not optimal for very heavy duty (i.e., 70 tons rather than 40 tons).

\section{My contribution}

This manuscript was prepared and written in collaboration between Jonas Ammenberg and me. The initial planning of the project and the literature review were mainly carried out by Jonas Ammenberg. I planned, performed, and transcribed all of the interviews and analyzed the interviews to write the results of the paper. The writing was mainly carried out by me, with the exception of the introduction and the discussion that were written by both of us. Jonas Ammenberg was also heavily involved in going through the manuscript to ensure the quality.

\subsection{Paper IV}

Ammenberg, J., Dahlgren, S. (2021). Sustainability Assessment of Public Transport, Part IA Multi-Criteria Assessment Method to Compare Different Bus Technologies. Sustainability, 13, 825. https://doi.org/10.3390/su13020825

\section{Background and aim}

The article departs from the perspective of Swedish regional transport authorities and focuses on the public procurement of bus transports. Many of these public organizations on the county level have the ambition to contribute to a transition involving the continued marginalization of fossil fuels and improved sustainability performance. However, there are several renewable bus technologies to choose between and it can be difficult to know what alternative (or combination) is preferable. Prior research and the authors' experiences indicate a need for improved knowledge and supportive methods on how sustainability assessments can support public procurement processes. 
The aim of Paper IV was to develop a multi-criteria assessment (MCA) method to support assessments of public bus technologies' sustainability. The method should:

- Be based on existing knowledge of practitioners and scientists

- Be adapted to the context and input from stakeholders, particularly Swedish regions' challenges related to the procurement of bus services and their views on sustainability

- Include common indicators such as monetary costs and function/quality but broaden the scope in relation to many existing methods

- Cover essential areas regarding sustainability and the most relevant aspects for the different technologies to be assessed

- Be relatively simple to use with a reasonable number of indicators to facilitate data collection and overview

$\circ$ When used, provide results for a wide range of indicators without weighting, thus leaving the users to decide based on their own preferences if any indicators are more important, such as local conditions and prioritized objectives.

\section{Key findings}

An MCA method was developed, consisting of four key areas and 12 indicators (Table 8). Each of the indicators has a scale ranging from very poor to very good (either with five or three steps) that can be used to assess whether a certain bus alternative is good in that indicator or poor. Table 9 shows an example of a scale belonging to the indicator energy security. The assessment of each alternative in each indicator should also be assessed based on the certainty of the results on a three-step scale $(*=$ high uncertainty, $* * *=$ low uncertainty).

Table 8. The key areas, key questions and indicators of the established MCA method.

\begin{tabular}{|c|c|}
\hline Key Areas and Key Questions & Indicators \\
\hline $\begin{array}{l}\text { Technical performance } \\
\text { Is the technology cost-efficient with a stable cost } \\
\text { development? }\end{array}$ & $\begin{array}{l}\text { - Technical maturity } \\
\text { - Daily operational availability }\end{array}$ \\
\hline $\begin{array}{l}\text { Economic performance } \\
\text { Is the technology cost-efficient with a stable cost } \\
\text { development? }\end{array}$ & $\begin{array}{l}\text { - Total cost of ownership } \\
\text { - Need for investments in infrastructure } \\
\text { - Cost stability }\end{array}$ \\
\hline $\begin{array}{l}\text { Environmental performance } \\
\text { Is the technology favorable concerning } \\
\text { environmental impacts and management of natural } \\
\text { resources? }\end{array}$ & $\begin{array}{l}\text { - Non-renewable primary energy efficiency } \\
\text { - Greenhouse gas emission savings } \\
\text { - Local/regional impact on land and aquatic } \\
\text { environments } \\
\text { - Air pollution } \\
\text { - Noise }\end{array}$ \\
\hline $\begin{array}{l}\text { Social performance } \\
\text { Is the technology favorable concerning societal and } \\
\text { social issues? }\end{array}$ & $\begin{array}{l}\text { - Energy security } \\
\text { - Sociotechnical system services }\end{array}$ \\
\hline
\end{tabular}


Table 9. Scale for the indicator "energy security".

\begin{tabular}{cc}
\hline Value & Scale Definition \\
\hline Very good & $\begin{array}{c}\text { More than } 90 \% \text { of the used fuel or electricity is produced within the actual region } \\
\text { based on resources from this region. }\end{array}$ \\
\hline Good & $\begin{array}{r}\text { More than } 90 \% \text { of the used fuel or electricity is produced within the nation, based on } \\
\text { resources of national origin. }\end{array}$ \\
\hline Satisfactory & $\begin{array}{c}\text { Meographically close to the nation, that the nation has long-term and stable business } \\
\text { relations with, based on resources from those countries. }\end{array}$ \\
\hline Poor & $\begin{array}{l}\text { More than } 90 \% \text { of the used fuel or electricity is produced in countries that are not } \\
\text { geographically close to the nation but which the nation has long-term and stable } \\
\text { business relations with, based on resources from those countries. }\end{array}$ \\
\hline Very poor & $\begin{array}{l}\text { More than } 90 \% \text { of the used fuel or electricity is produced within countries that are } \\
\text { not geographically close to the nation and which the nation does not have long-term } \\
\text { and stable business relations with, based on resources from those countries. }\end{array}$ \\
\hline
\end{tabular}

${ }^{1}$ Referring to the term region as used in Sweden, corresponding to county. Other areas could be used.

The method consists of both quantitative and qualitative indicators, as the purpose was to focus on the essential issues rather than on what can be easily measured. Weighting, which is otherwise common in multi criteria assessment projects, was avoided as it is a more "political step" and the importance of the indicators can vary between different regions.

Although the method was developed in a Swedish context, it addresses a challenge of general relevance - how to conduct sustainability assessments of transport technologies. The key areas and indicators would probably be relevant for the assessment of buses across the globe. Indicators dealing with technical and economic performance are likely generally applicable, while some adjustments can be reasonable for a few of those dealing with environmental and social performance, for example, adapting the levels of the scales to fit local conditions and available technology.

\section{My contribution}

This paper was prepared and written in collaboration between Jonas Ammenberg and me, from the idea to the final draft. My contribution was mainly in connection with the work that led up to the article, primarily related to the indicators established to compare the alternative bus technologies, and to the internal review and the publication process. The actual writing was mostly carried out by Jonas Ammenberg. The literature review was carried out by both authors (primarily Jonas Ammenberg) and through student projects by Éamon Magorrian, Agnes Lundgren, Anders Wilzén, Jacob Dahlstedt and Linnea Orsholm

\subsection{Paper V}

Dahlgren, S., Ammenberg, J. (2021). Sustainability Assessment of Public Transport, Part IIApplying a Multi-Criteria Assessment Method to Compare Different Bus Technologies. Sustainability, 13, 1273. https://doi.org/10.3390/su13031273 


\section{Background and aim}

Many Swedish regional transport authorities want bus fleets driven on renewable fuels. However, it may be difficult to know what technology, or combination of technologies, to choose. There is a need for improved knowledge and supportive methods for sustainability assessments that can support public procurement processes. In the companion article (Part I), a multi-criteria assessment (MCA) method for assessments of public bus technologies' sustainability was established, consisting of four key areas and 12 indicators. The aim of this article, Paper V, was to apply the MCA method developed in Part I on different bus technologies in order to do the following:

- Test the method and critically reflect upon its application and usefulness.

- Compare the different bus technologies, including buses driven on biomethane, ethanol, fatty acid methyl ester (FAME), HVO and electricity, and diesel and natural gas as reference technologies.

\section{Key findings}

Table 10 provides an overview of the assessment results. Generally, the alternatives using diesel engines have the best technical scores. The gas engines also perform well, while electric vehicles have a lower technical maturity. The picture is relatively scattered concerning the economic performance, and there is a higher uncertainty. Biomethane seemed to be slightly more expensive than diesel, HVO, FAME and natural gas, but cheaper than ethanol. However, the costs for using HVO could easily become more expensive. When considering the environmental dimension, fossil fuels are clearly non-sustainable alternatives. Biomethane outperforms the others from a generic environmental perspective and is the only alternative that can provide negative greenhouse gas emission levels. However, electric vehicles can be favorable in central city areas due to their low noise levels and as there are no local exhausts emissions, given that the electricity is produced from renewable sources. Also, the energy efficiency benefits of electric vehicles are most relevant in city areas. Regarding social performance, biomethane comes out best due to positive links to other socio-technical systems and energy supply services. Electric buses can both bring positive and negative effects.

Table 10. Overview of the assessment results

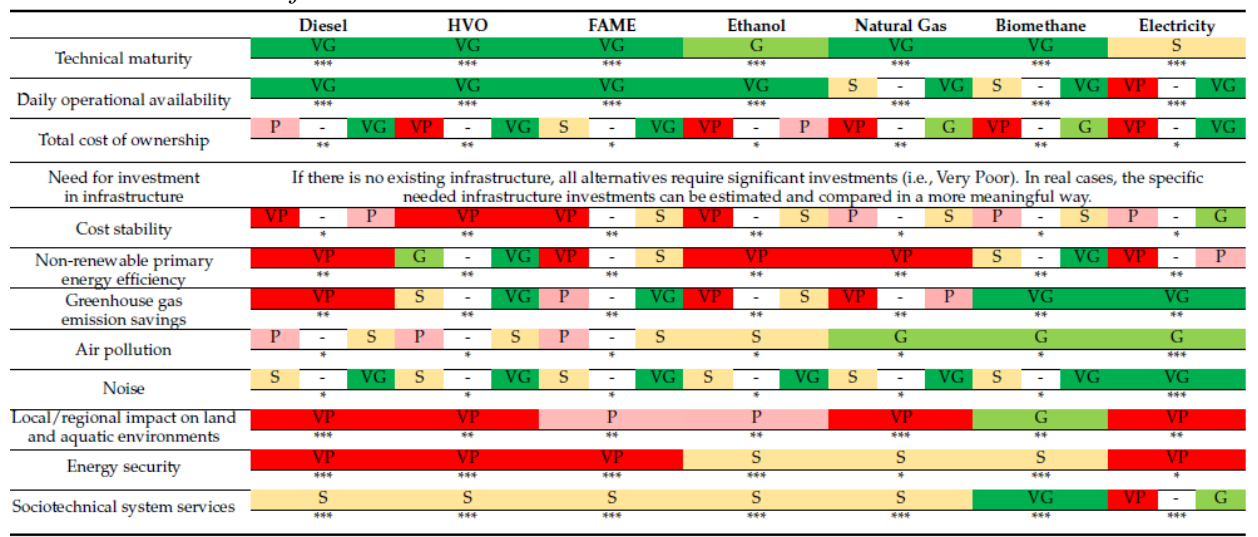


On an overarching level, the majority of the indicators worked relatively well. Some indicators were, however, more difficult to assess, both related to their definition and the availability of information, for example, cost stability that tries to estimate future costs or local/regional impacts on land and aquatic environments, which includes a wide range of different impacts that commonly vary due to local conditions.

The focus on the general Swedish market rather than more specific alternatives led to a wide range of values for several indicators and technologies. This scattered picture makes it hard to conclude what alternative is best. If the MCA method is used for a particular public procurement, it would be possible to use case-specific data for each technology and thus get more clear-cut answers with a higher level of certainty.

Despite all the challenges and opportunities to provide a more specific result, the MCA method can importantly contribute to improved knowledge on the sustainability of different bus technologies, as it helps in structuring relevant information and facilitating overview and more informed decision-making.

\section{My contribution}

This paper was prepared and written in collaboration between Jonas Ammenberg and me, from the idea to the final draft. My contribution was particularly related to producing the results of assessing the different bus technologies using the multi-criteria assessment method and writing most parts of the article, except some parts that Jonas Ammenberg was more involved in - for example the sections about cost stability and noise and the discussion. I also contributed strongly to the review and publication process. The literature review was carried out by both authors (primarily me) and through student projects by Éamon Magorrian, Agnes Lundgren, Anders Wilzén, Jacob Dahlstedt and Linnea Orsholm

\subsection{Paper VI}

Magnusson, T., Anderberg, S., Dahlgren, S., \& Svensson, N. (2020). Socio-technical scenarios and local practice - Assessing the future use of fossil-free alternatives in a regional energy and transport system. Transportation Research Interdisciplinary Perspectives, 5, 100-128. https://doi.org/10.1016/j.trip.2020.100128

\section{Background and aim}

The purpose of Paper VI was to demonstrate how sustainability transitions research can interact with local practice by means of socio-technical scenarios. The paper focused on a regional context and presented socio-technical scenarios that involved critical decisions on different fossil-free alternatives in a regional energy and transport system. With the intention to improve energy efficiency and reduce greenhouse gas emissions, the scenarios described processes that entail substitution of fossil fuels with renewables, as well as redeployment of renewable fuels into new application contexts, thus describing new utilization pathways. The paper highlighted the role of local policymakers and actor constellations in sustainability transitions.

The article presented four scenarios, which describe different ways of using biogas, biodiesel and electricity in four different applications: city buses, inter-city buses, heavy-duty trucks and industrial processes. Scenario 1 assumed continuous transport growth and that the share of 
biomethane in the city buses remained unchanged. Scenario 2 assumed that there would be a limited implementation of electric city buses, that the leftover biomethane would replace HVO on inter-city buses and that the leftover HVO would replace fossil diesel in heavy-duty trucks. Scenario 3 assumed that $90 \%$ of the city buses would be electrified and that the leftover biomethane would be used in heavy-duty trucks, substituting fossil diesel. Finally, Scenario 4 assumed that $90 \%$ of the city buses would be electrified and that the leftover biomethane would be used in manufacturing industries, substituting liquefied petroleum gas.

\section{Key findings}

The realization of Scenarios 2-4 depends on the involvement of different actors (Table 11) and investments in vehicles and infrastructure. Which actor will have to make these investments depends on several different things. For example, electrifying city buses means that the public transport authority will have to select charging strategies, design and plan infrastructure and integrate this in the planning of future bus services. Landowners must allow space for charging stations and the municipality must allow building permits. The use of biomethane in heavyduty trucks depends on haulers' willingness to invest in vehicles for liquefied biomethane, as well as transport buyers' willingness to demand and pay for transports that use renewable fuels. The use of biomethane in inter-city traffic requires specifically adapted vehicles. The public transport authority prefers double-decker coaches on these lines, which have not been available using biogas with liquefied biomethane until now. A number of actors need to be involved to start using LBG in coach buses - bus manufacturers, bus operators, the local energy utility (due to its biogas production and distribution), equipment suppliers, construction firms and the municipality (which owns the bus depot). More paramount than the individual activities are that all actors coordinate their work. For example, it does not matter if the public transport authority buys electric buses if the energy utility company does not have the electric grid capacity to enable charging stations at suitable locations. The possibility of realizing any of Scenarios 2-4 also depends on governmental policies, such as subsidy schemes for biogas and investment grants for the vehicles, the electric bus charging and so on. It also depends on local actors and their willingness to take part in activities and coordinate the changes. For Scenario 4, timing is extra important. Companies preparing for investments in their manufacturing systems will be more prone to changes than companies that have just realized such investments. 
Table 11. Key actors and activities in the scenarios.

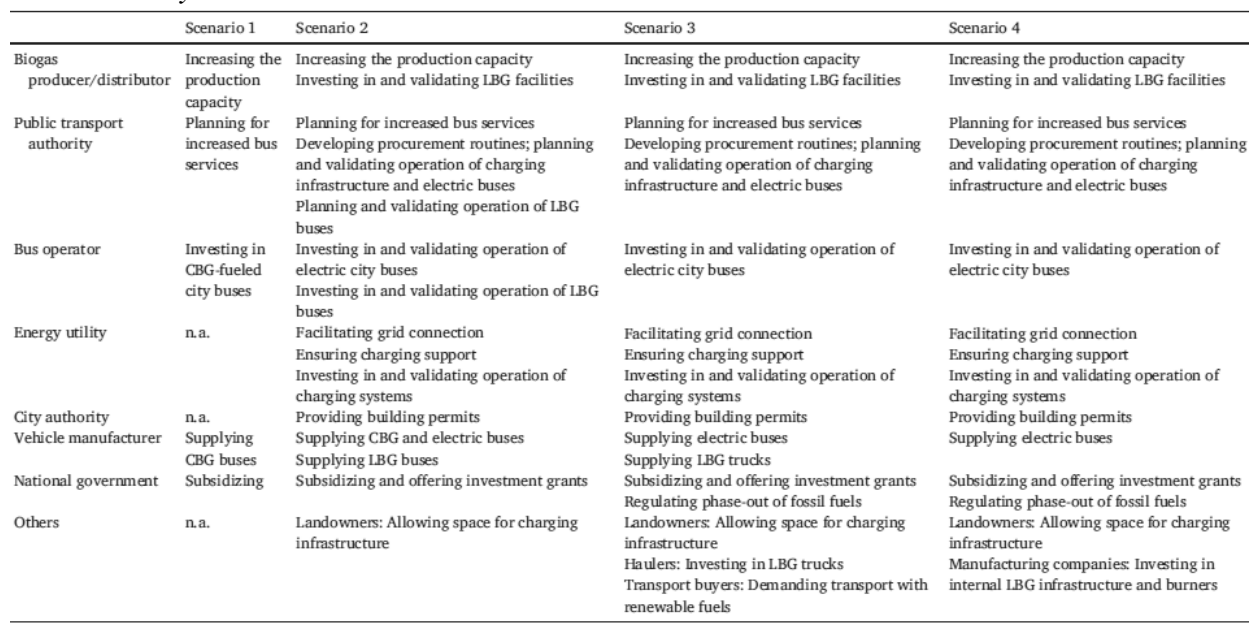

The realization of Scenarios 2-4 would lead to reduced energy use and decreased emissions of greenhouse gases. Since electric vehicles require less energy than combustion vehicles in the use phase, the amount of energy needed is reduced with increasing electrification. Regarding greenhouse gases, Scenarios 3 and 4 have larger reductions than the previous scenarios since more fossil fuels will be substituted. However, the greenhouse gas emissions reduction is almost equal for Scenarios 3 and 4 since fossil diesel is a more significant emitter of greenhouse gases than liquefied petroleum gas.

When the project started, the implementation of electric buses was a contested issue in the region. Local politicians urged the public transport authority to investigate the option of electric buses, while the representatives of the public transport authority maintained that they were satisfied with the current biogas bus operation. The public transport authority also dismissed the possibility of using biogas in inter-city traffic since there were no suitable coach buses available. A future implementation of electric buses in the region appeared distant. However, by the end of the project, the local contestation around electric buses seemed to have vanished and it was announced that there would be a limited implementation of electric buses during the next contract period. This project can have been part of overcoming that conflict, via the construction of the exploratory scenarios. The exploratory scenarios described possible realities rather than planned, and the project partners could contribute to the scenario construction without making any commitments. This meant that the scenarios helped elicit conflicting arguments, investigating the underlying basis for the arguments and searching for common standpoints. When evaluating the influence of the project during the last meeting, the involved local partners acknowledged that their project participation had broadened their understanding and thus strengthened their ability to assess different technology options.

\section{My contribution}

This paper was prepared and written in collaboration between Thomas Magnusson, Stefan Anderberg, Niclas Svensson and me. My contribution related mainly to the projects that led to 
the article, findings connected to Scenarios 3 and 4, the quantitative results and writing Section 7 ("Comparisons between the scenarios"). 


\section{The Swedish biogas system and its actors}

Biogas systems can be more complex than other bioenergy systems, partly due to the many different actors involved (Lantz et al. 2007). This chapter introduces the biogas system in Sweden and the involved actors.

\subsection{What biogas systems include}

A biogas system is here defined as a system with the production of biogas via anaerobic digestion of some kind of biomass and the subsequent use of biogas, digestate and other byproducts. Figure 1 shows an overview of what biogas systems usually consists of and how they relate to each other, with raw materials, production and use.

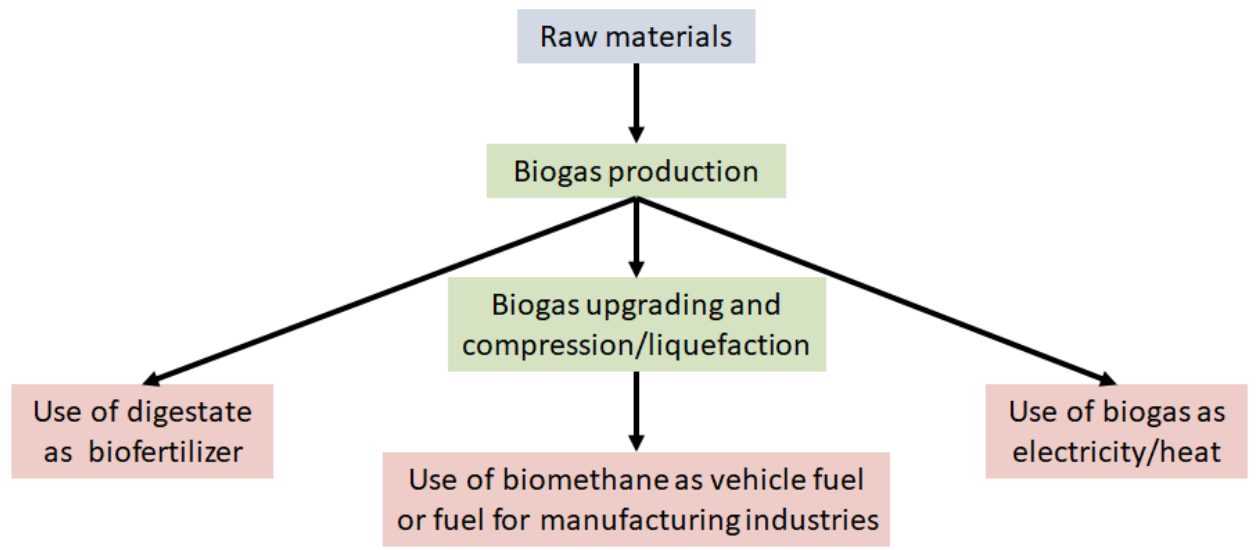

Figure 1. The biogas system in Sweden, with raw materials, production and use.

First, there has to be some kind of organic raw material that can be used for biogas production (also known as substrates). The substrates are then to be used in an anaerobic digestion process where the organic materials are digested and turned into a gas product consisting of mainly methane and carbon dioxide (biogas) and a nutrient-rich liquid/solid (digestate). The digestate can then be used as a biofertilizer, which has a positive impact on nutrient circulation (Lantz et al. 2007). The biogas can be used as renewable energy, either by being burned to produce heat or electricity or by being upgraded to a higher methane content and, for example, used as fuel for vehicles or manufacturing industries. Apart from these steps, a biogas system can also include other steps like distribution of the gas, distribution of the digestate and so forth.

\subsection{Different kinds of raw materials, production plants and usage areas}

The raw material, production and use connected to biogas systems is not homogenous. Instead, many different types of raw materials are used, and there are different kinds of production plants and different ways to use the products from the anaerobic digestion. Figure 2 gives an overview of the most common raw materials, production plants and usage areas in Sweden. 


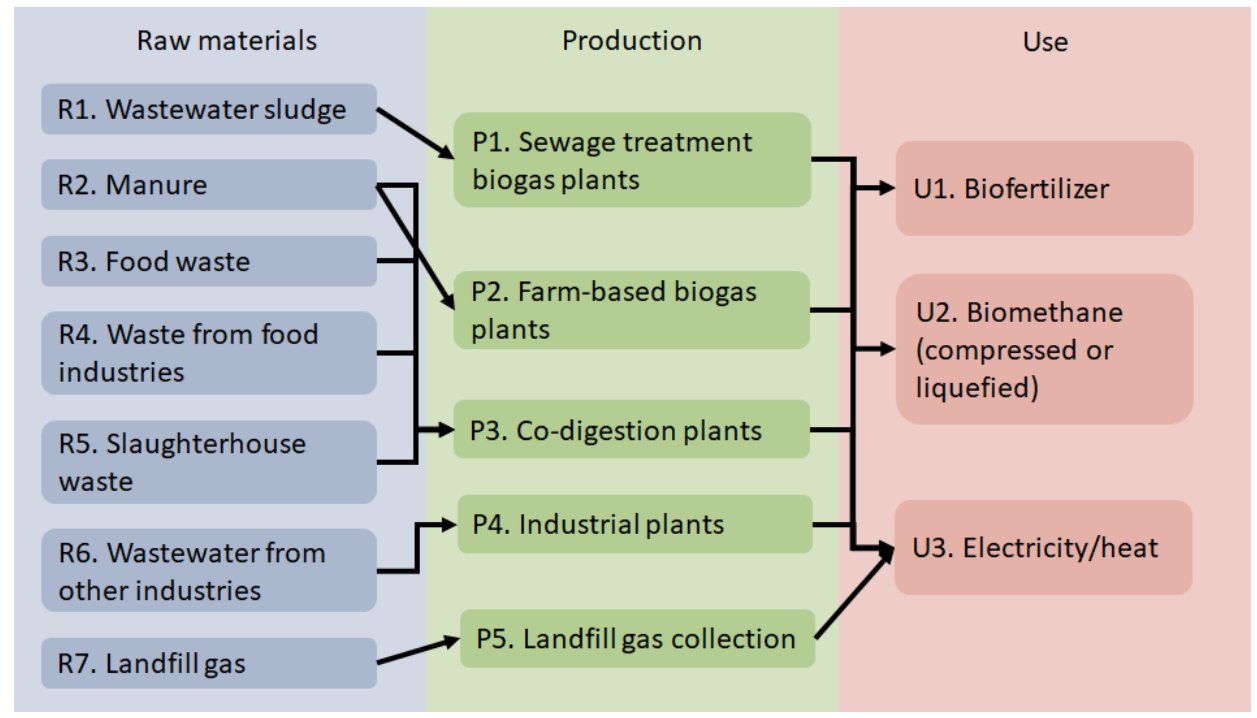

Figure 2. A simplified picture of what raw materials, production sites and usage areas are common in Sweden and how they are connected.

In Sweden in 2019, seven different kinds of raw materials were primarily used for biogas production: waste water sludge (32\%), food waste $(20 \%)$, manure $(10 \%)$, slaughter house waste $(8 \%)$, waste from food industries $(6 \%)$, landfill gas $(7 \%)$ and industrial waste water $(5 \%)$ (Klackenberg 2020). Apart from these there were also some energy crops (2\%) and other substrates (10\%) (Klackenberg 2020). Almost all raw material used in Sweden for biogas production is thus waste substrates of different kinds. Using local raw materials like waste and manure to produce energy in this manner can have a positive impact on energy security (Piwowar, Dzikuć, and Adamczyk 2016; Surroop, Bundhoo, and Raghoo 2019).

In the production stage, the different substrates are not necessarily used together in the same kind of production plant. The wastewater sludge is used in biogas plants within sewage treatment plants, and landfill gas is collected at old municipal landfills that contain organic materials and where the natural anaerobic digestion is still ongoing. However, since 2005, there has been a ban on landfilling with organic materials and the biogas produced from landfills is thus only what remains of previous landfills and has decreased dramatically in recent decades. There is also dedicated industrial anaerobic digestion, using industrial wastewater to produce biogas, and farm plants using manure. The other substrates, such as food waste, slaughterhouse waste, and waste from food industries, are mainly used in co-digestion plants where different substrates are digested together. These divisions are, however, not strict. There are, for example, large amounts of manure used in co-digestion plants, and there are wastewater treatment plants that also use food waste and waste from food industries. There are also farm plants using slaughterhouse waste and waste from food industries apart from the manure.

In the consumption phase, mainly two different products from the anaerobic digestion are used - digestate and biogas. Among the digestate produced from Swedish biogas systems, $87 \%$ was used as fertilizer in 2019. The biogas collected at landfills is primarily used as electricity or 
heat, or it is flared (burned without using the energy for anything). The rest of the biogas is primarily upgraded $(64 \%)$ or used as heat $(19 \%)$ or electricity $(2 \%)$.

\subsection{Actors involved in the biogas system in Sweden}

The different types of raw materials, production plants and usage areas all involve various actors. Figure 3 gives an overview of the type of actor that is mainly involved in each respective raw material, production plant and usage area that was previously shown in figure 2 .

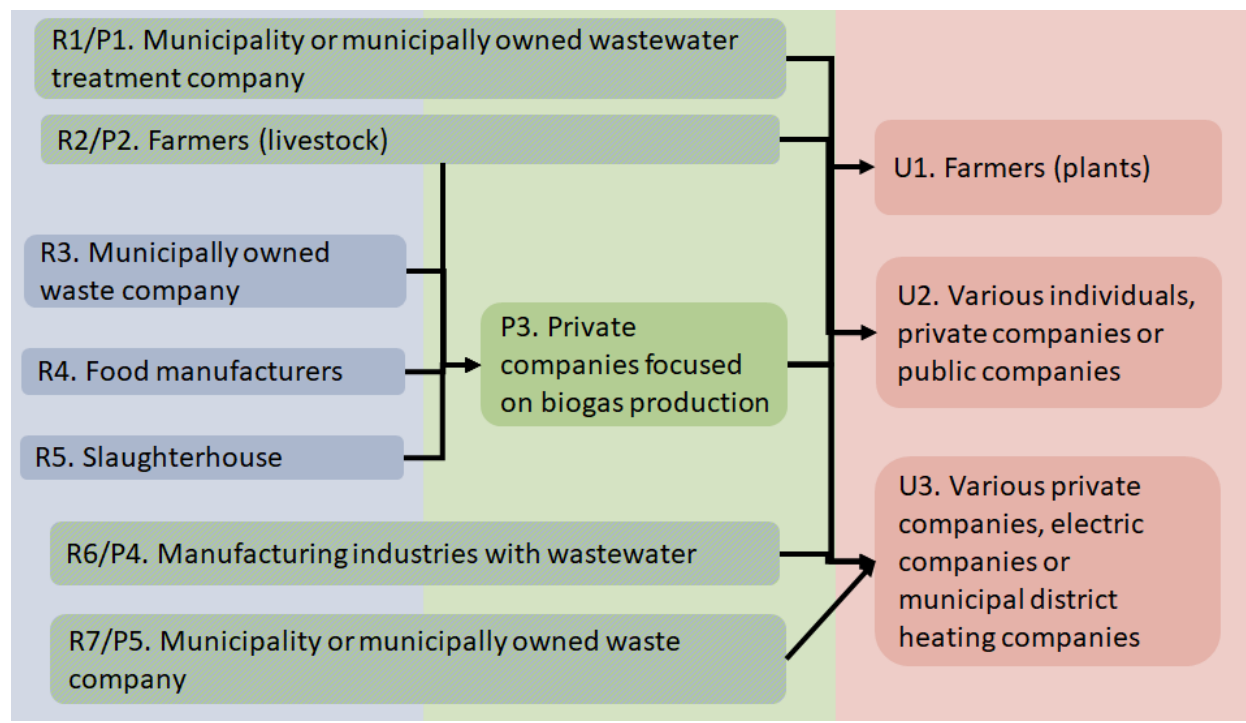

Figure 3. An overview of what actors are usually part of the biogas system, based on the raw materials, production sites and usage areas presented in Figure 2.

Swedish municipalities are responsible for making sure that there are services such as water, wastewater treatment, waste management, child care, schools and elderly care (Sveriges Kommuner och Regioner 2021a). As such, wastewater sludge, food waste and landfill gas are all substrates that are connected to the municipal responsibilities. Producing biogas is thus not necessarily the main reason for the anaerobic digestion for municipalities and those types of wastes. Regarding wastewater treatment, biogas is a by-product of treating sludge (Fallde and Eklund 2015). There are regulations about collecting landfill gas from old landfills to reduce methane emissions, and there are regulations that forbid organic waste from being landfilled and thus have to be dealt with in other ways (for example, via anaerobic digestion).

Livestock farmers have manure from their livestock, sometimes more than they are allowed to spread on their own fields. The resulting digestate from anaerobic digestion of manure results in a better biofertilizer than manure (Lantz et al. 2007). This biofertilizer can then be used by the same farmers on their own fields or by other farmers specializing in growing plants. Biofertilizer from biogas production can not only be used for common farming but also enable organic farming (Ottosson et al. 2020) since, for example, manure that is turned into digestate has an improved fertilization effect (Lantz et al. 2007). 
Manufacturing companies, such as pulp and paper mills, sometimes generate wastewater. The anaerobic digestion process can be used in their internal wastewater treatment processes with biogas as a byproduct from the treatment. Regarding co-digestion plants, they use substrates originating from a number of different actors, such as food industries, slaughterhouses, and municipally owned waste companies. Co-digestion plants are most commonly run by private companies, but a large portion of the production facilities are owned by public organizations (Ottosson et al. 2020). Generally speaking, Swedish municipalities have been responsible for the largest share of investment in biogas production (Ottosson et al. 2020).

The users of biogas are a large number of individual entities, households, private companies or public organizations that require fuel for vehicles, manufacturing, heating or electricity.

Biogas systems thus have connections to several different sectors, such as the agricultural sector, the industrial sector and the municipal sector (Lantz et al. 2007) - which makes the system more complex since it has to be aligned and embedded with actors and practices on all sides (Wirth et al. 2013).

\subsection{Actors that use biomethane}

This thesis focuses primarily on the second example of users in Figure 3 - the use of biomethane. As Ottosson et al. (2020) found, there are five market segments that either use biomethane or where the target is that biomethane should be used (Table 12). These market segments involve different actors.

Table 12. Current and targeted market segments for biomethane in Sweden, based on Ottosson et al. (2020).

$\begin{array}{ll}\text { Market segment } & \text { Actor primarily connected to the use } \\ \text { Buses } & \text { Bus operators } \\ \text { Cars } & \begin{array}{l}\text { Taxi operators, municipalities, companies, } \\ \text { consumers }\end{array} \\ \text { Light trucks and refuse trucks } & \text { Municipalities, companies } \\ \text { Long-haulage trucks } & \text { Haulers } \\ \text { Industry } & \text { Manufacturing firms }\end{array}$

Public organizations can be involved in several ways. The municipal responsibilities include, for example, schools that require school buses and waste management that requires refuse trucks - which can run on biomethane. Swedish regions are responsible for health care, dental care and regional development (Sveriges Kommuner och Regioner 2021b) and can have several vehicles connected to those areas. The regions and municipalities together run the public transport system, where biomethane can be used in the buses.

Private companies are generally involved in two different ways - fuel for transports or fuel for manufacturing processes. Any company that uses transport, such as cars, small trucks or longhaulage trucks, can use biomethane in those vehicles - either in their own vehicles or via haulers or other transport companies. Regarding manufacturing processes, some manufacturing industries require heat for their processes and can use biogas or biomethane for that purpose. 


\subsection{Other actors and actor constellations}

This is a simplified picture, and there exist other actor constellations. For example, the distributor of the gas is not necessarily the producer. Instead, Ottosson et al. (2020) found that biogas distribution is dominated by three large multinationals with a few other small local distributors. There are companies focused on taking care of nutrient-rich by-products like digestate, making biofertilizers out of them and then selling it to farmers (Mirata, Eklund, and Gundberg 2017). Regarding wastewater treatment and waste management, it is common that they are run as municipally owned joint-stock companies (Peedu and Meier 2020) - but there are examples that the municipalities have procured the activity from external private companies (Swedish Energy Agency 2016).

There are other actors involved in the biogas system that have been excluded from the previous figures. Municipalities are responsible for the planning within the municipality and have to agree on any construction related to biogas. There are also different companies that produce the technical equipment needed connected to anaerobic digestion, upgrading, compressing, gas engines, refueling stations and so forth. Governmental authorities introduce policies that affect biogas use and production, such as investment grants connected to biogas and tax exemptions for biomethane used as vehicle fuel (Ottosson et al. 2020). Other policies affect biogas systems in less direct ways, such as the landfilling ban for organic waste and the tac on commercial fertilizers (Lantz et al. 2007). 


\section{Results}

This chapter presents the results to the three research questions, which are based on the findings in the appended articles.

\subsection{How biogas compares with other potential alternatives}

The multi-criteria assessment done on bus technologies (Papers IV and V) found that biomethane-powered buses are technically mature and have a high expected operational availability. There are no well-grounded doubts regarding the technical performance. The other possible alternatives are also technically mature except ethanol, which is slightly less technically mature, and electric buses, which are still a new technology with more uncertainties regarding performance. Refueling of biogas buses can be done without any significant negative impacts on the desired timetables. Electric buses, on the other hand, have a risk of negatively influencing timetables or requiring additional buses as fast charging requires time during routes, which also reduces flexibility. Several negative technical aspects regarding using biomethane can be found when looking at a broader range of possible uses than only buses. Such negative technical aspects can, for example, be that biomethane requires large tank volumes and thus limits the range of heavy-duty vehicles in comparison to diesel alternatives and that there is a need to constantly cool the system if liquefied biomethane is used to deal with the volume and range issue (Paper I). The lack of refueling infrastructure and limitations of the supply of biogas are also disadvantages. Even if there is no general shortage of biogas today for current uses, it would be difficult for biogas to become an important fuel for shipping due to the limited supply and the large size of ships.

Using biomethane in buses is more expensive for the buyer/user than diesel, HVO, FAME and natural gas. Bus purchasing, as well as maintenance and fuel costs, are slightly more expensive. Looking at the costs connected to other usage areas than buses, heavy trucks that use methane are more expensive to purchase than a common diesel-powered truck, and due to the volumes of the liquefied methane cisterns on ships, it is often too expensive to retrofit existing ships and therefore new ships are required. If socio-economic costs had been included, the results would be different. The costs would then most likely be lower than diesel due to the reduction of socioeconomic costs in relation to, for example, local pollution and $\mathrm{CO}_{2}$ emissions. Regarding the cost stability of biomethane buses, the picture is divided and very uncertain. On the one hand, there has historically been only a small number of local actors involved in biogas production, and lack of competition may lead to higher prices, and a rapidly increasing demand can lead to higher prices (Paper V). On the other hand, biomethane is among the options with a higher likelihood of stable costs. The local character of inputs provides the possibility of stable raw material prices in the long term, and the consensus among leading politicians in Sweden to support biomethane being used for transports is likely to contribute to foreseeable conditions.

Biogas is a renewable fuel that has a very low climate change impact when it is produced by the kind of resources used in Sweden (i.e., organic waste, manure, and wastewater treatment sewage). Together with electric buses using electricity from nuclear, hydro and wind power, biogas was the best option for buses considering climate change impact in the MCA study. Biogas was the only alternative that could have a positive impact on greenhouse gas emissions and not only a reduced negative impact. However, estimations of greenhouse gas emissions 
related to biogas, and the other alternatives, vary considerably in the literature due to differences in assumptions, study contexts and system delimitations.

Prospects of reducing local air pollution from road transports have a historically important role in the interest in biomethane. This was also the primary reason why the regional authority in Östergötland, Sweden (Paper VI) started to use biomethane in its public transports. Biomethane is today, together with natural gas and electricity, the best option for buses regarding air pollution. Electricity can, however, be better than biogas if the electricity is originating fully from renewable sources. The interest in methane in the shipping sector is also increasing due to its low atmospheric emissions. Previously, biogas has also had advantages connected to noise levels. Today, however, the main difference between the noise of possible transport alternatives is that electric vehicles, like buses, are much more silent in urban traffic than any internal combustion alternatives - including biomethane. The MCA study found that biogas can positively impact the local/regional land and the aquatic environment - in contrast to the other studied alternatives, which all had different degrees of negative impacts. Biogas can improve the nutrient supply and nutrient availability as well as reduce nutrient leakages and decrease odors from some of the substrates. However, there can also be slightly negative impacts on the local/regional land and aquatic environment via increased risk of odors from the biogas production plants and by using digestate from wastewater treatment. Using digestate from wastewater treatment as fertilizer, which can often contain elevated concentrations of undesirable substances, can mean an increased risk of spreading those undesirable substances. However, studies on plants fertilized with digested wastewater treatment sludge have not shown higher concentrations of some undesirable substances than for plants from other agricultural lands.

Historically, biogas development has also been connected to the interest of increasing national energy security. The MCA study found that biomethane, together with ethanol and natural gas, were the best alternatives for buses in consideration of national energy security. It was also found that biogas can have several positive links to different socio-technical systems, such as waste and wastewater management, and that these systems work better if they are linked to biogas systems. The only other alternative that had any strong links to other socio-technical systems was electric buses, which can have either a negative and positive impact on the energy system via, for example, reducing or increasing peaks in the system. 


\subsection{Why decision-makers in Sweden are interested in or hesitant towards biogas}

According to the findings from the studies connected to the appended papers, private companies and public organizations in Sweden find it interesting to use biogas for several different reasons (Table 13). Several of these are connected to that starting to use biogas can be seen as an environmental action. Environmental actions like switching to biogas can be important for the company, can help public organizations with goals on fossil independence/reduced greenhouse gas emissions, can help companies take market shares and can be a way to make the world a more sustainable place so that future generations can continue working in the company. There are also some reasons connected to previous experiences of biogas or biogas being used in other parts of the company/organization. Regarding private companies working with public procurement contracts, the company can start using biogas if the contract requires it. It has been identified that private companies are concerned with the future stability of fuels, and biogas has a positive view since there is a positive political climate, stable access and an expansion of infrastructure. Public organizations, on the other hand, seem more interested in that biogas can increase resource efficiency through using waste and increased recirculation of nutrients. Another important aspect for public organizations seems to be that locally produced biogas can help with local energy production and that local biogas production, in general, makes organizations more interested in using it. However, it is not surprising that those reasons were identified among public organizations since regional development is part of the regional responsibilities and because municipalities are usually working towards more business within their municipalities. 
Table 13. Summary of identified reason that make decision-makers interested in using biogas.

\begin{tabular}{|c|c|}
\hline Private companies & Public organizations \\
\hline $\begin{array}{l}\text { + Environmental actions are important for the } \\
\text { company. } \\
+ \text { Environmental actions are a way for the } \\
\text { company to take market shares. } \\
+ \text { The company is a family business and has } \\
\text { long-term multigenerational thinking } \\
\text { connected to sustainability. } \\
+ \text { Biogas is a good alternative since it is } \\
\text { produced from waste. } \\
+ \text { The company already produces biogas as a } \\
\text { by-product. } \\
+ \text { The company has previous good } \\
\text { experiences with biogas. } \\
+ \text { Biogas is a promising option considering } \\
\text { the current political climate. } \\
+ \text { The current expansion of the infrastructure } \\
\text { is promising for the future of biogas. } \\
+ \text { There is relatively stable access to biogas } \\
\text { in Sweden. } \\
+ \text { Public procurements can require biogas to } \\
\text { be used by the company if the company wins } \\
\text { the procurement. }\end{array}$ & $\begin{array}{l}\text { + As a renewable fuel, biogas can help } \\
\text { towards national, regional or local goals on } \\
\text { fossil independence. } \\
\text { + Biogas can help towards national, regional } \\
\text { or local goals on reduced greenhouse gas } \\
\text { emissions. } \\
\text { + If biogas is already used by other parts of } \\
\text { the organization, they can be more prone } \\
\text { towards starting to use it in other areas as well } \\
\text { since there can be existing infrastructure, } \\
\text { knowledge about it and so forth. } \\
+ \text { If there is local biogas production, the } \\
\text { organization can be more interested in using } \\
\text { biogas. } \\
+ \text { If local substrates are used, biogas can help } \\
\text { towards goals on local energy production. } \\
+ \text { Using biogas can increase resource } \\
\text { efficiency by using waste products to } \\
\text { produce the biogas. } \\
+ \text { Biogas systems can increase the } \\
\text { recirculation of nutrients. } \\
+ \text { Using biomethane in public transport can } \\
\text { help show the inhabitants the circularity of } \\
\text { the biogas system, with what is achieved by, } \\
\text { for example, collecting organic waste. }\end{array}$ \\
\hline
\end{tabular}

Several factors that can make private companies and public organizations in Sweden hesitant to use biogas were identified (Table 14). Both private companies and public organizations had misgivings connected to the cost - that biogas is too expensive, requires changes to the vehicles or infrastructure (which is costly), and there can be limited availability of suitable options, which can make it hard to estimate how much it will cost to use biogas. Among public organizations, there is also a challenge that the cost of using biogas is not necessarily on the same actor that reaps the potential economic benefits. A common user of biogas within public organizations is public transport, which is often run via a regionally owned public transport company or administration. This public transport authority is usually separate from the other regional responsibilities, such as health and regional development. The same goes for municipalities, which usually run waste and wastewater separately in their own companies or administrations.

Apart from reservations about the cost, other reasons for hesitation were also identified. There are still challenges with the lack of biogas, infrastructure or suitable alternatives that can use biogas. Both private companies and public organizations identified better options than biogas for urban areas, with less noise and less local emissions. However, the reasons for why this was 
interesting differed. For private companies, it related mostly to the possibility of night-time deliveries in urban areas, and for public organizations it related partly to that less emissions and noise can affect how the city is planned and built. Regarding private companies working with public procurement contracts, the company will likely not start using biogas if the contract does not require it. Another challenge that connected both private companies and public organizations is a lack of knowledge, for example, connected to making the decision-makers understand the wide variety of benefits of using biogas. Among private companies, there was also a challenge with "old knowledge", for example, bad experiences with early versions of biogas technology or a belief that biogas can only be used if there is a production plant nearby.

Table 14. Summary of identified reasons that make decision-makers hesitant towards biogas.

\begin{tabular}{|c|c|}
\hline Private companies & Public organizations \\
\hline $\begin{array}{l}\text { - Too expensive. } \\
\text { - Requires a change of vehicles, } \\
\text { infrastructure, etc. } \\
\text { - Short-sightedness of current policies and } \\
\text { the risk of rapid changes in the policy } \\
\text { climate. } \\
\text { - A lack of available biogas suitable for the } \\
\text { company to use. } \\
\text { - A lack of infrastructure for biogas in } \\
\text { Sweden or outside of Sweden if the company } \\
\text { deals with international transports. } \\
\text { - The currently existing biogas technologies } \\
\text { might not be suitable for the needed use. } \\
\text { - There are options that are better suited for } \\
\text { urban areas than biogas (especially for night- } \\
\text { time deliveries), with less noise and less local } \\
\text { emissions. } \\
\text { - If the company works with public } \\
\text { procurement and the procurement does not } \\
\text { require biogas use. } \\
\text { - Difficult to be knowledgeable about biogas } \\
\text { and other alternatives. } \\
\text { - Old beliefs from old experiences with } \\
\text { biogas or that biogas can only be used with a } \\
\text { production plant nearby. }\end{array}$ & $\begin{array}{l}\text { - Biogas can be more expensive than other } \\
\text { alternatives. } \\
\text { - A limited availability of suitable biogas } \\
\text { alternatives can make it harder to estimate the } \\
\text { costs. } \\
\text { - The costs of using the biogas are not on the } \\
\text { same actor that reaps potential economic } \\
\text { benefits. } \\
\text { - The currently existing biogas technologies } \\
\text { might not be suitable for the needed use, or } \\
\text { there are only very limited options. } \\
\text { - If there is no suitable refueling } \\
\text { infrastructure for biogas } \\
\text { - Some options are better suited for urban } \\
\text { areas than biogas with less noise and less } \\
\text { local emissions, affecting how a city is } \\
\text { planned and built. } \\
\text { - It is difficult to make the decision-makers } \\
\text { fully understand the wide variety of benefits } \\
\text { of biogas. }\end{array}$ \\
\hline
\end{tabular}




\subsection{How decision support can be used in decision-making to deal with complexities}

Two different decision support methods are in focus in this research, socio-technical scenarios and multi-criteria assessments. They were used in different studies to support decisions that partly included biogas use - electrification of city buses and the subsequent use of biogas (Paper VI) and different alternative technologies for buses, including biogas (Papers IV and V).

In the socio-technical scenario study (Paper VI), different development paths were explored as possible images of the future, looking at public transport in a city in Sweden. In the current situation, biomethane was used to fuel all the city buses in the city. However, the study looked at the electrification of some of the buses in the future, and how the leftover biomethane could be used instead. The outcomes of the development paths were evaluated in terms of energy use and greenhouse gas emissions, but what was needed to realize these futures was also discussed - what actors would need to be involved, what the actors would need to do and so forth.

In the research connected to multi-criteria assessments, a multi-criteria assessment method was developed to compare different fuel options for buses, and then this method was used for assessing different alternatives, among them biogas (Papers IV and V). The assessment was divided into four key areas - technical performance, economic performance, environmental performance and social performance. Within these key areas, a total of 12 indicators were established and then used to assess the alternatives: technical maturity, daily operational availability, total cost of ownership, need for investments in infrastructure, cost stability, nonrenewable primary energy efficiency, greenhouse gas emission savings, local/regional impact on land and aquatic environments, air pollution, noise, energy security and socio-technical system services. Each of these indicators was assessed using a scale from Very Poor to Very Good, as well as assessed based on how certain the results were.

Both these two methods can be used in decision-making connected to biogas, but they focus on different parts of the complexities surrounding the decision to use biogas. The socio-technical scenarios were primarily focused on the actors, while the scenarios were developed through a participatory process. Through participating in this process, the involved actors meant that they got support to elicit conflicting arguments, investigate the underlying basis for the arguments and search for common standpoints. Apart from the actors that were part of the project, the results of the scenario study also included what would need to be done in order to realize the scenarios, namely, what actors would need to do what. Overall, the socio-technical scenarios showed a potential to deal with the complexities connected to the many actors involved in the production and use of biogas and identify how to achieve a change when all of them have to act together, instead of it being possible for a single actor to by itself decide and make the required changes.

Even if the multi-criteria assessment method was also based on a participatory process with a large involvement of different actors, the assessment results are less focused on actors and actions needed to realize a certain future. Their focus was more on developing a broad picture of the impacts of biogas or other fuel alternatives. The establishment and use of the method presented knowledge about the alternatives in a wider spectrum than what is usually the case and provided an overview of how the alternatives compare to each other in both technical, 
economic, environmental and social terms. Multi-criteria assessment methods revealed a great potential to create conditions for more well-considered decisions and increase the safety of the decisions by systematically assess all relevant aspects. 


\section{Discussion}

This chapter further analyses and discusses the results by connecting them to previous research. It starts with a section connected to the first research question, followed by two sections connected to the second research question and two sections connected to the third research question. The chapter then discusses the results in a more general perspective by tying them back to transition management.

\subsection{Biogas compared to other alternatives}

A large part of the interest in biogas stems from that biogas is an environmentally and socially valid alternative. However, the costs for the user seem to be higher than the more traditional fossil fuel alternatives as well as some other renewable alternatives. This can hinder biogas use since, according to findings by Ammenberg et al. (2018), economic considerations often focus on vehicle costs without studying the broader picture and considering things like branding. However, this disparity in costs is not set in stone and might change in the future. Regarding the fuel itself, fossil fuels might become more expensive in the future due to policies or scarcity. $\mathrm{HVO}$, which is a very popular fuel alternative for heavy vehicles in Sweden, has become scarcer and more expensive in recent years - and there is a high risk that this development will continue further. Apart from the fuel is also the fact that biomethane vehicles are still much newer and less common than diesel vehicles, which are cheaper to buy. However, since biomethane vehicles are newer and less common, part of the disparity in cost might come from exactly that fact - since low production scales can lead to more expensive production (Kemp, Schot, and Hoogma 1998). Another factor is that HVO and RME are both used in common diesel vehicles and are thus a smaller change from the current standard, while biomethane vehicles require altered motors, fuel storage and so on. Developing new products is a long and expensive process (Kemp et al. 1998), and since there are fewer biomethane vehicles produced there is a risk that the development cost is split between fewer produced vehicles. If the interest in biogas increases, there might thus be a chance that biomethane becomes less expensive compared to alternatives that are more commonly used today.

Apart from that costs might change in the future, there are also other reasons for how biogas compares to other alternatives that are not set in stone. It is obvious from the interview studies that the interest in biogas among private companies has changed during the last couple of years. The earlier interviews (Paper II) pointed towards uncertainties in policies connected to biogas and that decision-makers were uncertain of biogas due to the risk of changed policies. However, the interviews carried out two to three years later (Paper III) pointed more towards that biomethane was perceived as a good option for the future and that the development of biogas was going in the right direction. During those two to three years, there were several changes in a positive direction for biogas. For example, the government set up an investigation on how biogas could be supported (Swedish Government Official Reports 2019), both of the major Swedish auto manufacturers presented new versions of heavy trucks that ran on liquefied biomethane (Alpman 2018) and a Finnish company decided to make large investments in infrastructure that would radically increase the number of refueling stations for primarily liquefied methane in Sweden (Gasum 2018). Infrastructure is a common "chicken-and-egg" problem since there is no interest in vehicles if there is no refueling infrastructure at the same time as there is no interest in refueling infrastructure if there are no vehicles (Leibowicz 2018). According to Leibowicz (2018), there needs to be a diffusion of infrastructure before there is a 
diffusion of the vehicles since the infrastructure enables vehicle adaption. These findings showed similarities to that - when there was more infrastructure for biomethane for heavy vehicles, the decision-makers seemed more interested in using biomethane in their trucks. However, the findings also pointed towards another chicken-and-egg problem - interest and investment from other actors. In the later interviews (Paper III), several public companies mentioned that biogas seemed promising since other actors were investing in using biogas and that ethanol was not promising because there were no actors investing in it. It thus seems as if interest in new technologies spread to others, but that someone has to take the first step.

Regarding what piece of the puzzle biogas is most suitable for, both my findings and previous findings (Aldenius et al. 2021; Ammenberg et al. 2018) point towards alternatives other than biogas that might work better for transports in central areas. Electric and fuel cell vehicles, which do not have an internal combustion engine, can have less local air pollution and are less noisy. Those aspects are not only important for public organizations and how the cities are built but also for private companies that want to move goods during the night. According to Aldenius et al. (2021), it is also considered more important to work with air pollution and noise in cities, and so far, all procurements of electric buses have been for urban traffic. Biomethane might instead be better suited for surrounding areas or more heavy-duty vehicles, such as longdistance buses, working machines and heavy trucks (Ammenberg et al. 2018). Regarding buses, Aldenius et al. (2021) agreed that biomethane has a wider range of uses and works for all kinds of bus traffic.

Even though biomethane is more suitable to use in some area than others, an important thing to remember is that biomethane can only be one part of a solution. There also needs to be other parts of the solution to manage to change from unsustainable technologies. One of the actors in focus in this thesis, public organizations, have in many cases already come far in their change towards renewable alternatives, with a reduction of greenhouse gas emissions from buses by 85 \% between 1999 and 2019 (Swedish Environmental Protection Agency 2021). Municipalities have also had a very important role for previous investments in biogas production, and the development of public buses running on biomethane was a crucial part of the development of biomethane use in Sweden (Fallde and Eklund 2015). However, electric vehicles have benefits that can make them particularly interesting for city buses in urban areas. Magnusson and Berggren (2018) showed that there can be a competition between city buses fueled by biomethane and electricity, and that such a competition can worsen already existing difficulties with high costs. Instead of competing with each the other alternatives, there needs to be a move towards renewable alternatives as a whole in competition with fossil alternatives. It has already been seen by Bergek et al. (2008) that benefits from one alternative can spill over to another. Changing to electric buses in an area where it might be more suitable to use electric than biomethane can be a good thing - if the freed up biogas is actually used to substitute a worse alternative, like fossil fuels, in another area (Paper VI).

\subsection{Narrow perspectives in decision-making}

A common reason among decision-makers for interest in biogas is that it is an environmental action that can reduce the environmental impacts. Primarily, this seems to be motivated by a desire to reduce the use of fossil fuels and greenhouse gas emissions. However, in some cases air pollution and noise were also mentioned and, in the case of public organizations, recycling of nutrients and resource efficiency. A narrow scope on climate change, and partly air pollution 
and noise, rather than on many other types of environmental and social impacts has also been observed in many other recent studies reviewed by Kügemann and Polatidis (2019). Since biogas systems have broader advantages, this narrow focus that seems to be common, especially in private companies, misses other aspects that biogas systems have positive impacts on, for example, energy security, nutrient circulation or synergies with other socio-technical systems. As Ammenberg et al. (2018) found, decision-makers that decide on transport alternatives seem to have a limited focus on the broad range of positive effects that can be linked to biogas systems.

However, some decision-makers have a broad perspective. Using biogas can, according to one interviewed company, help decision-makers work towards a more circular economy, and many others also see the potential for anaerobic digestion when it comes to society moving in that direction (e.g. Abad et al. 2019; Stoknes et al. 2016). During the last decade, circular economy has become a more influential concept in the EU (Domenech and Bahn-Walkowiak 2019) and Sweden (Niskanen, Anshelm, and McLaren 2020). Further increased interest in circular economy will certainly increase interest in biogas systems and further stimulate decisionmakers' future interest in using biogas.

In recent years, an increasing number of actors have started to base their work towards sustainability on the UN Sustainable Development Goals. This can allow actors, such as public organizations like municipalities, to get a broader systems perspective into sustainability implementation (Krantz and Gustafsson 2021). Since biogas systems can fit into the sustainable development goals in a number of different ways (Hagman and Eklund 2016), further interest in the sustainable development goals and in broader perspectives can increase interest in biogas in order for the decision-makers to work towards several goals at the same time.

However, having a broader perspective is not necessarily only connected to catching different kinds of impacts - there can also be difficulties with how the many different aspects are considered. In the multi-criteria assessment, we choose to only include non-renewable primary energy efficiency and not more commonly used energy efficiency measures like fuel efficiency. By studying non-renewable primary energy efficiency, we focused more on the entire life cycle of the used alternative rather than only on a small part of it. This can be connected back to systems thinking and looking at the entire system and its effects rather than only at a small part. However, fuel efficiency has been a large part of previous comparisons between different regional public transports (Swedish Association of Local Authorities and Regions 2015). In public procurements, requirements connected to energy use have generally focused on decreasing fuel use (Aldenius et al. 2021) without considering the production of the fuel. In the last couple of years, such requirements on energy efficiency have become more common (Aldenius et al. 2021). This may affect the technology choice against biogas since gas engines have slightly lower efficiency than conventional engines and electric engines have a much higher efficiency. However, if the fuel production is also considered instead of only the user phase, the picture changes. This can be exemplified by the results of the multi-criteria assessment on buses as well as by Gustafsson et al. (2018) that also presented another energy performance indicator that considers the entire life cycle better than the previously used fuel efficiency. 


\subsection{Differences between different decision-makers}

Public organizations seem to be more interested in broader sustainability implications, while private companies focus more on public perception and the market. This is not really surprising, considering the differences between the two. Private companies make money from sales and are thus more likely to try and use the environmental initiatives in a way that the company gains from (for example, trying to improve the public perception of the company). In contrast, public organizations are responsible for different public services, such as health care, waste management or public transport. These responsibilities can, in different ways, connect to biogas. Regions also have the responsibility to work towards strengthening regional growth and development. This makes it more likely that they consider a broader spectrum of impacts from biogas systems.

However, that public organizations have a stronger interest in sustainable options than private companies can definitely be contested. Ammenberg et al. (2018) found that public organizations may simply focus on the cheapest way to reach internal objectives without further considerations. At the same time, economic considerations often play a major role in the choice of vehicle, often focusing on vehicle costs (Ammenberg et al. 2018), which might hinder biomethane use since biomethane vehicles are often more expensive than fossil fuel vehicles. Private companies, on the other hand, seem to be better at having an economic view that includes different kinds of branding - even if the benefits are often not seen directly. Since private companies are dependent on sales, it is completely understandable that they consider their brand and how to improve it more than a public organization does. For private companies, the public opinion of biogas might thus be more important than that biogas is a multifunctional solution that can address several challenges simultaneously.

Regarding public organizations, there can also be the difficulty that the economy of one part of the organization is not necessarily well connected to the others or other public organizations. Several responsibilities within public organizations that connect to biogas, such as wastewater treatment and waste management in the municipalities, are often handled by municipally owned or private companies, and thus have to function like any other joint-stock company. One such example is in connection with the previous biogas development in Linköping - the municipality owned company responsible for waste management and wastewater sewage, as well as another company responsible for public transport within the city (Fallde and Eklund 2015). Even though the municipality was responsible for both the waste/wastewater and the public transport, they were handled separately (Fallde and Eklund 2015). Apart from benefits connected to waste and wastewater, there are also many other benefits of biogas systems that can affect parts of the responsibilities of public organizations. Air pollution in the EU causes added costs for society via, for example, health treatment costs and loss of workdays, and reduced emissions of air pollutants can reduce those costs (Koolen and Rothenberg 2019). However, in connection with several workshops that have been carried out, it was made clear that the public transport authorities could not count that they would benefit from any lessened costs for the healthcare system that might occur from the changes towards alternatives with, for example, less air pollution - even though the same regional authorities are responsible for both public transport and the healthcare system in Sweden. Ammenberg et al. (2018) found a unit in a public organization that thought electric vehicles were economically profitable for them since they could charge them for free at the buildings they rented - but they rented the buildings from 
another unit of the public organization, who then had to bear the increased electricity costs. Biogas can have positive benefits in several different areas and be an important part of several socio-technical systems. This can result in obstacles towards using biogas if only the user costs are considered (which tend to be more expensive) without looking at the broader benefits of the use of the biogas.

\subsection{Dealing with sustainability issues when there is no completely good alternative to decide upon}

There are no solutions to sustainability challenges that are the best in every possible impact (Brown et al. 2010; Rittel and Webber 1973). Biogas is often seen as a good environmental option since it can have several positive benefits. However, it is not the best alternative considering every possible aspect - it has disadvantages as well in comparison to the other alternatives. This has also been observed by other research focused on comparing different alternatives or looking at alternatives using a broader spectrum of impacts (e.g. Ammenberg and Feiz 2017; Hansson et al. 2019; Sehatpour et al. 2017). No matter what decision is reached, there will be a need for trade-offs.

Decision support is particularly useful and well-motivated in situations where one deals with alternatives that compare differently, with no alternative being unequivocally good. As Ness et al. (2007) wrote, sustainability assessment methods are supposed to help decision-makers make their decision by assisting them in evaluating what effects the different actions have. Decision support focused on sustainability can, however, deal with this challenge in different ways. The developed multi-criteria assessment method dealt with it by trying to be transparent and facilitate data collection and overview, leaving for the decision-maker to decide based on their own preferred trade-offs. In contrast, many other decision support methods with similar uses use weighting, where the results are clumped together into a single, final score based on how important the impact category is considered to be (so-called weights) (Kügemann and Polatidis 2019). The existence of such weights clearly shows a need for trade-offs between different solutions - if there were a solution that was the best option in all impact categories, there would be no need to decide upon which of the impact categories are more important. However, the use of weights as part of the decision support, before the support tool reaches the decisionmaker is not entirely without problems since it can reduce the transparency and make it harder for the user to understand and verify different assumptions. Reasonings among decision-makers can vary, and they might thus be prone to make different trade-offs. This is not only among decision-makers using the final decision-support tool; different trade-offs have been observed in the studies by Tzeng et al. (2005) and Vahdani et al. (2011). Such differences can have high impacts on the final results, and cause the results to show opposing conclusions (Kügemann and Polatidis 2019).

\subsection{How decision support can aid decision-makers}

That there are different alternatives to choose between, that all have their own positive and negative impacts, is not the only complexity that needs to be dealt with when making decisions. Although socio-technical scenario analysis can be used to study impacts from possible alternative decisions, the focus is on other parts of the decision - how the change can be achieved and who needs to be part of it. With their connection to numerous actors in several sectors, biogas systems are an evident example of that this part of a decision is also important 
to consider. It is not only the potential user of a technology that has to decide on starting to use the alternative since any change has to work together with subsequent changes in the other parts of the socio-technical system. Multi-criteria assessment and socio-technical scenario analysis can thus both help decision-makers deal with the complexities in their decisions, although in slightly different ways. The multi-criteria assessments focused more on the different impacts the decision would have on the environment, society, and the user's economy, while the sociotechnical scenario analysis focused more on how such changes could be realized. Should it not then be possible to use both these decision support methods together for the same decision? The findings clearly show that it is not only the decision-making that is complex but also decision support tools themselves. Decision support might be needed for different parts of the decisionmaking process and thus require differences in focus and what can be achieved by different methods instead of striving for a single integrated method that cannot be expected to work for all aspects of a decision.

\subsection{Implications connected to transition management}

For decision-making in a private company or public organization, with actors that decide whether or not to use a new technology, the structure of decision-making processes can be quite similar to the framework developed by Loorbach (2010). The companies or organizations need to decide what the aim should be (strategic), how they can reach that aim (tactical), carry out actions to reach the aim (operational) and reflect upon how it works (reflexive). The research here is mainly connected to decision-making of whether or not to use a particular more sustainable alternative and how such decisions can be supported, and the connection is thus primarily to the first two parts of the framework - deciding on what to do and how to do it. As an alternative that reduces the environmental impact, the findings show how biogas can be of interest to companies and organizations and what visions they can strive towards by adopting biogas. The findings also clearly connect to the tactical step by showing what barriers there are to the development of the company or organization deciding to use biogas. These barriers towards the use of biogas can be important to consider not only for the company but also in a larger perspective with policy-makers to make them understand what might hinder the development of biogas use. As previously stressed, to gain acceleration in a transition and to expand markets requires that a number of actors decide to use the technology. Regarding decision support, the multi-criteria assessment mainly supports the decision-maker by showing what the impacts would be from deciding to use particular alternatives, which is in a rather early stage of decision-making when the actor is just deciding what direction to take. In contrast, socio-technical scenario analysis can also support the decision-maker in a later stage of the decision-making connected more to the tactical step - how can the desired direction, the desired future, be reached?

Even if the research in connection with this thesis is mainly tied to the strategic and tactical steps, the other two (operational and reflexive) also come into play at times. During the interviews, there were private companies that explained that they had tried using biogas and how that trial affected their choice. In one case, a company had had a previous bad experience when it tried using biomethane, and after a reflexive step when the trial was evaluated, it became much more reluctant to use biomethane in the future, that is previous operational and reflexive steps affected the current strategic steps in a negative direction towards future use of biomethane. In another case, a company had previously started to use some heavy trucks fueled by LBG and found them to work well, which made them more interested in further use of 
biomethane - previous operational and reflexive steps thus affected the current strategic steps in a positive direction towards future use of biomethane. This was not only the case for the private companies that were interviewed but also the public organizations. Biomethane had previously been used by many of the public organizations in primarily public transport, and thus several of the public organizations already had positive experiences from biomethane use that affected their view on biomethane when deciding upon what they wanted to do - as well as affecting other similar actors by sharing their experiences. 


\section{Conclusions}

This research aimed at contributing to a greater understanding of what the decisions to use alternative technologies are based on and how these decisions can be supported, and it did this by focusing on three research questions.

The findings connected to how biogas systems compare to other potential alternatives show that biogas is an alternative with environmental advantages compared to other potential options. However, electric vehicles are better concerning local impacts like air pollution and noise and can thus be better suited for urban areas. Biogas systems also have some social advantages, like increased energy security and positive impacts on other socio-technical systems. It can, however, be more expensive to use biogas than many of the other alternatives, although the costs can be expected to be more stable than, for example, HVO. Biomethane in buses is, like the other alternatives excepting electric buses, a technically mature alternative with good daily operational availability. However, for other uses, there can be disadvantages like a lack of refueling infrastructure or a limited range due to the large tank volumes.

Decision-makers in Sweden find it interesting to use biogas for a number of different reasons, although the primary reason is that biogas is perceived as a good environmental option. The public organizations part of the research seemed to have broader perspectives than the private companies and at times included things like energy security, nutrients and showing inhabitants the circularity of biogas systems. The private companies seemed to be more focused on that biogas or other environmental actions could benefit the image of the company, but also on that biogas seems like a potential long-term alternative considering the current market and policy climate. Decision-makers in Sweden are hesitant to use biogas primarily due to economic or policy aspects or due to a lack of technical maturity (such as lack of infrastructure or lack of suitable technology). The findings also show that there, for example, can be a lack of knowledge among decision-makers and that there might be renewable alternatives that the decision-maker finds more suitable to their particular situation.

Decision support can be used in decision-making to ease the decision by, for example, making it more transparent, creating conditions for more well-considered decisions and helping to make a systematic assessment of the relevant aspects. Different decision support tools can help with this in different ways. Multi-criteria assessment can help the decision-maker focus on many different impacts at the same time and making the decision process transparent so that potential trade-offs can be well-founded. Socio-technical scenario analysis can, on the other hand, help the decision-maker understand how the wanted changes can be realized - what needs to be done, what actors need to be involved and so on.

This research, connecting back to the overall aim, has contributed to a greater understanding of decisions connected to the use of alternative technologies by, for example, showing what kind of factors can be relevantly connected to decisions on using alternative technologies, what private and public decision-makers consider in their decision-making and how decision support can be used. More generally, the research contributed by showing the complexity of these kinds of decisions and how transition management connects to decisions on a smaller scale among private companies and public organizations. The research also has empirical and methodological contributions. The empirical contribution lies primarily in the contributed 
knowledge of different alternative uses for biogas and what alternatives could be used instead, and deeper knowledge about certain possibilities - especially CBG and other alternative fuels that could be used in buses. The methodological contribution lies in how decisions can be supported via either multi-criteria assessment (focusing on how different alternatives compare against a number of impacts connected to, e.g., environment or society) or socio-technical scenario analysis (focusing on what impacts different future scenarios could have and how such scenarios could be realized).

In the future, several different areas could be interesting for further studies. As previously discussed, multi-criteria assessments and socio-technical scenario analysis partly looks at different aspects of decision-making, and it would thus be interesting to see whether they can be combined for the same decision to give support to the decision-maker in a fuller spectrum. Another interesting area to look further into is that of the different decision-makers and usage areas. Both Papers II and VI looked at a mix of different usage areas, but it could be interesting to study one or several of them in more depth in order to better understand what the possibilities for using biogas in that area would be. The previously established multi-criteria assessment tool could also be used as a basis to see how the decision connected to usage in, for example, trucks, shipping and industries could be supported. Regarding the different decision-makers, it would also be interesting to have a dedicated study for the difference in how private companies reason regarding using more sustainable alternatives and how public organizations reason. 


\section{References}

Abad, Vanessa, Romina Avila, Teresa Vicent, and Xavier Font. 2019. "Promoting Circular Economy in the Surroundings of an Organic Fraction of Municipal Solid Waste Anaerobic Digestion Treatment Plant: Biogas Production Impact and Economic Factors.” Bioresource Technology 283:10-17. doi: 10.1016/j.biortech.2019.03.064. Aldenius, Malin, Panagiota Tsaxiri, and Helene Lidestam. 2021. "The Role of Environmental Requirements in Swedish Public Procurement of Bus Transports." International

Journal of Sustainable Transportation 1-22. doi: 10.1080/15568318.2021.1879975. Alpman, Marie. 2018. "Het marknad för lastbilar på iskall gas.” Energigas Sverige. Ammenberg, Jonas, Stefan Anderberg, Tomas Lönnqvist, Stefan Grönkvist, and Thomas Sandberg. 2018. "Biogas in the Transport Sector-Actor and Policy Analysis Focusing on the Demand Side in the Stockholm Region." Resources, Conservation and Recycling 129:70-80. doi: 10.1016/j.resconrec.2017.10.010.

Ammenberg, Jonas, and Sofia Dahlgren. 2021. "Sustainability Assessment of Public

Transport, Part I-A Multi-Criteria Assessment Method to Compare Different Bus

Technologies." Sustainability 13(2):825. doi: 10.3390/su13020825.

Ammenberg, Jonas, and Roozbeh Feiz. 2017. "Assessment of Feedstocks for Biogas

Production, Part II-Results for Strategic Decision Making." Resources, Conservation and Recycling 122:388-404. doi: 10.1016/j.resconrec.2017.01.020.

Anderberg, Stefan, and Sofia Dahlgren. 2019. Transport- och drivmedelsscenarier: Östergötland 2030.

Association Technique Energie Environment. 2018. Statistiques Filière Biogaz - Juillet 2018 [Statistics Biogas Sector - July 2018]. (2018).

Azar, Christian, and Kristian Lindgren. 2003. "Global Energy Scenarios Meeting Stringent CO2 Constraints - Cost-Effective Fuel Choices in the Transportation Sector." Energy Policy 16.

Bachmann, Nathalie. 2013. Swiss Country Report. IEA Bioenergy (2013).

Baier, Urs, Matthieu Buchs, and Sandra Hermle. 2018. Switzerland - 2018 Update. Bioenergy Policies and Status of Implementation. IEA Bioenergy (2018).

Baumgartner, Rupert J., and Jouni Korhonen. 2010. "Strategic Thinking for Sustainable Development.” Sustainable Development 18(2):71-75. doi: 10.1002/sd.452.

Bergek, Anna, Staffan Jacobsson, Bo Carlsson, Sven Lindmark, and Annika Rickne. 2008.

"Analyzing the Functional Dynamics of Technological Innovation Systems: A Scheme of Analysis." Research Policy 37(3):407-29. doi: 10.1016/j.respol.2007.12.003.

Bergek, Anna, Staffan Jacobsson, and Björn A. Sandén. 2008. “'Legitimation' and 'Development of Positive Externalities': Two Key Processes in the Formation Phase of Technological Innovation Systems.” Technology Analysis \& Strategic Management 20(5):575-92. doi: 10.1080/09537320802292768.

Bergek, Anna, and Ingrid Mignon. 2017. "Motives to Adopt Renewable Electricity

Technologies: Evidence from Sweden.” Energy Policy 106:547-59. doi: 10.1016/j.enpol.2017.04.016.

Beria, Paolo, Ila Maltese, and Ilaria Mariotti. 2012. "Multicriteria versus Cost Benefit Analysis: A Comparative Perspective in the Assessment of Sustainable Mobility."

European Transport Research Review 4(3):137-52. doi: 10.1007/s12544-012-0074-9.

Bernstein, Jay Hillel. 2015. "Transdisciplinarity: A Review of Its Origins, Development, and

Current Issues." Journal of Research Practice 11(1):21.

Björner Brauer, Hanna, and Jamil Khan. 2021. "Diffusion of Biogas for Freight Transport in Sweden: A User Perspective.” Journal of Cleaner Production 312:127738. doi: 10.1016/j.jclepro.2021.127738. 
Brown, Valerie, A., Peter M. Deane, John A. Harris, and Jacqueline Y. Russell. 2010. “Towards a Just and Sustainable Future." Pp. 3-15 in Tackling Wicked Problems: Through the Transdisciplinary Imagination. Taylor \& Francis Group.

Browne, David, and Lisa Ryan. 2011. "Comparative Analysis of Evaluation Techniques for Transport Policies.” Environmental Impact Assessment Review 31(3):226-33. doi: 10.1016/j.eiar.2010.11.001.

Bryman, Alan. 2015. Social Research Methods. 5th edition. Oxford university press. Bryman, Alan, Saul Becker, and Joe Sempik. 2008. "Quality Criteria for Quantitative, Qualitative and Mixed Methods Research: A View from Social Policy.” International Journal of Social Research Methodology 11(4):261-76. doi: 10.1080/13645570701401644.

Brynolf, Selma, Erik Fridell, and Karin Andersson. 2014. "Environmental Assessment of Marine Fuels: Liquefied Natural Gas, Liquefied Biogas and Bio-Methanol.” Journal of Cleaner Production 74:86-95. doi: 10.1016/j.jclepro.2014.03.052.

Bunn, Derek W., and Ahti A. Salo. 1993. "Forecasting with Scenarios." European Journal of Operational Research 68(3):291-303. doi: 10.1016/0377-2217(93)90186-Q.

Cappannelli, Michela, Christophe McGlade, Pharoah Le Feuvre, and Tim Gould. 2020. Outlook for Biogas and Biomethane - Prospects for Organic Growth. World Energy Outlook Special Report.

Carlsson, B., and R. Stankiewicz. 1991. "On the Nature, Function and Composition of Technological Systems." Journal of Evolutionary Economics 1:93-118.

Cheng, Wenjuan, Andrea Appolloni, Alessio D'Amato, and Qinghua Zhu. 2018. "Green Public Procurement, Missing Concepts and Future Trends - A Critical Review." Journal of Cleaner Production 176:770-84. doi: 10.1016/j.jclepro.2017.12.027.

Dahlgren, Sofia. 2020. "Biogas-Based Fuels as Renewable Energy in the Transport Sector: An Overview of the Potential of Using CBG, LBG and Other Vehicle Fuels Produced from Biogas.” Biofuels. doi: 10.1080/17597269.2020.1821571.

Dahlgren, Sofia, and Jonas Ammenberg. 2021. "Sustainability Assessment of Public Transport, Part II-Applying a Multi-Criteria Assessment Method to Compare Different Bus Technologies.” Sustainability 13(3):1273. doi: 10.3390/su13031273.

Dahlgren, Sofia, Wisdom Kanda, and Stefan Anderberg. 2019. "Drivers for and Barriers to Biogas Use in Manufacturing, Road Transport and Shipping: A Demand-Side Perspective." Biofuels 1-12. doi: 10.1080/17597269.2019.1657661.

Danish Energy Agency. 2017. "Biogas in Denmark.” Retrieved May 30, 2018 (https://ens.dk/en/our-responsibilities/bioenergy/biogas-denmark).

Domenech, Teresa, and Bettina Bahn-Walkowiak. 2019. "Transition Towards a Resource Efficient Circular Economy in Europe: Policy Lessons From the EU and the Member States." Ecological Economics 155:7-19. doi: 10.1016/j.ecolecon.2017.11.001.

Fallde, Magdalena, and Mats Eklund. 2015. "Towards a Sustainable Socio-Technical System of Biogas for Transport: The Case of the City of Linköping in Sweden." Journal of Cleaner Production 98:17-28. doi: 10.1016/j.jclepro.2014.05.089.

Farla, Jacco, Floortje Alkemade, and Roald A. A. Suurs. 2010. "Analysis of Barriers in the Transition toward Sustainable Mobility in the Netherlands." Technological Forecasting and Social Change 77(8):1260-69. doi: 10.1016/j.techfore.2010.03.014.

Fenton, Paul, and Sara Gustafsson. 2017. "Moving from High-Level Words to Local Action - Governance for Urban Sustainability in Municipalities." Current Opinion in Environmental Sustainability 26-27:129-33. doi: 10.1016/j.cosust.2017.07.009.

Gasum. 2018. Gasum Corporate Responsibility 2018. (2018).

Geels, F. W., and R. P. J. M. Raven. 2007. "Socio-Cognitive Evolution and Co-Evolution in Competing Technical Trajectories: Biogas Development in Denmark (1970-2002)." 
International Journal of Sustainable Development \& World Ecology 14(1):63-77. doi: 10.1080/13504500709469708.

Geels, Frank, and Rob Raven. 2006. "Non-Linearity and Expectations in Niche-Development Trajectories: Ups and Downs in Dutch Biogas Development (1973-2003)."

Technology Analysis \& Strategic Management 18(3-4):375-92. doi: 10.1080/09537320600777143.

Geels, Frank W. 2002. "Technological Transitions as Evolutionary Reconfiguration Processes: A Multi-Level Perspective and a Case-Study." Research Policy 31:125774.

Geels, Frank W., Benjamin K. Sovacool, Tim Schwanen, and Steve Sorrell. 2017. "The Socio-Technical Dynamics of Low-Carbon Transitions." Joule 1(3):463-79. doi: 10.1016/j.joule.2017.09.018.

Guba, Egon G., and Yvonna S. Lincoln. 1994. "Competing Paradigms in Qualitative Research."

Guenther, Edeltraud, Anne-Karen Hueske, Kristin Stechemesser, and Lioba Buscher. 2013. "The 'Why Not'-Perspective of Green Purchasing: A Multilevel Case Study Analysis." Journal of Change Management 13(4):407-23. doi: 10.1080/14697017.2013.851950.

Gustafsson, Marcus, Niclas Svensson, and Stefan Anderberg. 2018. "Energy Performance Indicators as Policy Support for Public Bus Transport - The Case of Sweden." Transportation Research Part D: Transport and Environment 65:697-709. doi: 10.1016/j.trd.2018.10.008.

Hagman, Linda, and Mats Eklund. 2016. The Role of Biogas Solutions in the Circular and Bio-Based Economy. Linköping University: Biogas Research Center.

Hansson, Julia, Stina Månsson, Selma Brynolf, and Maria Grahn. 2019. “Alternative Marine Fuels: Prospects Based on Multi-Criteria Decision Analysis Involving Swedish Stakeholders." Biomass and Bioenergy 126:159-73. doi: 10.1016/j.biombioe.2019.05.008.

Hekkert, M. P., R. A. A. Suurs, S. O. Negro, S. Kuhlmann, and R. E. H. M. Smits. 2007. "Functions of Innovation Systems: A New Approach for Analysing Technological Change." Technological Forecasting \& Social Change 74:413-32. doi: 10.1016/j.techfore.2006.03.002.

Hijazi, O., S. Munro, B. Zerhusen, and M. Effenberger. 2016. "Review of Life Cycle Assessment for Biogas Production in Europe." Renewable and Sustainable Energy Reviews 54:1291-1300. doi: 10.1016/j.rser.2015.10.013.

Hillman, Karl M., and Björn A. Sandén. 2008. "Exploring Technology Paths: The Development of Alternative Transport Fuels in Sweden 2007-2020." Technological Forecasting \& Social Change 75:1279-1302. doi: 10.1016/j.techfore.2008.01.003.

Hofman, Peter S., Boelie E. Elzen, and Frank W. Geels. 2004. "Sociotechnical Scenarios as a New Policy Tool to Explore System Innovations: Co-Evolution of Technology and Society in The Netherland's Electricity Domain." Innovation 6(2):344-60. doi: 10.5172/impp.2004.6.2.344.

Hölscher, Katharina, Julia M. Wittmayer, and Derk Loorbach. 2018. "Transition versus Transformation: What's the Difference?" Environmental Innovation and Societal Transitions 27:1-3. doi: 10.1016/j.eist.2017.10.007.

Hughes, Thomas P. 1987. "The Evolution of Large Technological Systems." in The Social Construction of Technological Systems.

Huttunen, Markku J., Ville Kuittinen, and Ari Lampinen. 2017. Suomen Biokaasulaitosrekisteri N:O 21 [Finish Biogas Register No. 21]. University of Eastern Finland (2017). 
Huttunen, Suvi, Paula Kivimaa, and Venla Virkamäki. 2014. "The Need for Policy Coherence to Trigger a Transition to Biogas Production." Environmental Innovation and Societal Transitions 12:14-30. doi: 10.1016/j.eist.2014.04.002.

International Energy Agency. 2020. Key World Energy Statistics 2020. Paris.

Jain, Sarika, David Newman, Ange Nizhou, Harmen Dekker, Pharoah Le Feuvre, Hannah Richter, Frederic Gobe, Charlotte Morton, and Rebecca Thompson. 2019. Global Potential of Biogas. London, UK: World Biogas Association.

Kemp, René, Johan Schot, and Remco Hoogma. 1998. "Regime Shifts to Sustainability through Processes of Niche Formation: The Approach of Strategic Niche Management.” Technology Analysis \& Strategic Management 10(2):175-98. doi: 10.1080/09537329808524310.

Klackenberg, Linus. 2020. Produktion och användning av biogas och rötrester år 2019. ER 2020:25. Bromma: Swedish Energy Agency.

Klitkou, Antje, Simon Bolwig, Teis Hansen, and Nina Wessberg. 2015. "The Role of Lock-in Mechanisms in Transition Processes: The Case of Energy for Road Transport." Environmental Innovation and Societal Transitions 16:22-37. doi: 10.1016/j.eist.2015.07.005.

Köhler, Jonathan, Frank W. Geels, Florian Kern, Jochen Markard, Elsie Onsongo, Anna Wieczorek, Floortje Alkemade, Flor Avelino, Anna Bergek, Frank Boons, Lea Fünfschilling, David Hess, Georg Holtz, Sampsa Hyysalo, Kirsten Jenkins, Paula Kivimaa, Mari Martiskainen, Andrew McMeekin, Marie Susan Mühlemeier, Bjorn Nykvist, Bonno Pel, Rob Raven, Harald Rohracher, Björn Sandén, Johan Schot, Benjamin Sovacool, Bruno Turnheim, Dan Welch, and Peter Wells. 2019. “An Agenda for Sustainability Transitions Research: State of the Art and Future Directions." Environmental Innovation and Societal Transitions 31:1-32. doi: 10.1016/j.eist.2019.01.004.

Koolen, Cedric D., and Gadi Rothenberg. 2019. "Air Pollution in Europe.” Chemsuschem 12(1):164-72. doi: 10.1002/cssc.201802292.

Korstjens, Irene, and Albine Moser. 2018. "Series: Practical Guidance to Qualitative Research. Part 4: Trustworthiness and Publishing." EUROPEAN JOURNAL OF GENERAL PRACTICE 24(1):120-24.

Krantz, Venus, and Sara Gustafsson. 2021. "Localizing the Sustainable Development Goals through an Integrated Approach in Municipalities: Early Experiences from a Swedish Forerunner." Journal of Environmental Planning and Management 1-19. doi: 10.1080/09640568.2021.1877642.

Kügemann, Martin, and Heracles Polatidis. 2019. "Multi-Criteria Decision Analysis of Road Transportation Fuels and Vehicles: A Systematic Review and Classification of the Literature." Energies 13(1):157. doi: 10.3390/en13010157.

Lajunen, Antti. 2014. "Energy Consumption and Cost-Benefit Analysis of Hybrid and Electric City Buses.” Transportation Research Part C: Emerging Technologies 38:115. doi: 10.1016/j.trc.2013.10.008.

Lantz, Mikael, Mattias Svensson, Lovisa Björnsson, and Pål Börjesson. 2007. "The Prospects for an Expansion of Biogas Systems in Sweden-Incentives, Barriers and Potentials." Energy Policy 35(3):1830-43. doi: 10.1016/j.enpol.2006.05.017.

Laurent, Alexis, Stig I. Olsen, and Michael Z. Hauschild. 2012. "Limitations of Carbon Footprint as Indicator of Environmental Sustainability." Environmental Science \& Technology 46(7):4100-4108. doi: 10.1021/es204163f.

Leibowicz, Benjamin D. 2018. "Policy Recommendations for a Transition to Sustainable Mobility Based on Historical Diffusion Dynamics of Transport Systems.” Energy Policy 119:357-66. doi: 10.1016/j.enpol.2018.04.066. 
Lijó, Lucía, Sara González-García, Jacopo Bacenetti, and Maria Teresa Moreira. 2017. “The Environmental Effect of Substituting Energy Crops for Food Waste as Feedstock for Biogas Production.” Energy 137:1130-43. doi: 10.1016/j.energy.2017.04.137.

Lincoln, Yvonna, and Egon Guba. 1985. Naturalistic Inquiry. California: SAGE Publications. Lindfors, Axel, and Jonas Ammenberg. 2020. "Using National Environmental Objectives in Green Public Procurement: Method Development and Application on Transport Procurement in Sweden." Journal of Cleaner Production 124821. doi: 10.1016/j.jclepro.2020.124821.

Lindfors, Axel, Roozbeh Feiz, Mats Eklund, and Jonas Ammenberg. 2019. “Assessing the Potential, Performance and Feasibility of Urban Solutions: Methodological Considerations and Learnings from Biogas Solutions." Sustainability 11(14):3756. doi: $10.3390 /$ su11143756.

Lönnqvist, Tomas, Stefan Grönkvist, and Thomas Sandberg. 2017. "Forest-Derived Methane in the Swedish Transport Sector: A Closing Window?" Energy Policy 105:440-50. doi: 10.1016/j.enpol.2017.03.003.

Loorbach, Derk. 2010. "Transition Management for Sustainable Development: A Prescriptive, Complexity-Based Governance Framework.” Governance 23(1):161-83.

Lundmark, Robert, Sara Anderson, Anders Hjort, Tomas Lönnqvist, Sven-Olof Ryding, and Patrik Söderholm. 2021. "Establishing Local Biogas Transport Systems: Policy Incentives and Actor Networks in Swedish Regions." Biomass and Bioenergy 145:105953. doi: 10.1016/j.biombioe.2020.105953.

Magnusson, Thomas, Stefan Anderberg, Sofia Dahlgren, and Niclas Svensson. 2020. "SocioTechnical Scenarios and Local Practice - Assessing the Future Use of Fossil-Free Alternatives in a Regional Energy and Transport System.” Transportation Research Interdisciplinary Perspectives 5:100128. doi: 10.1016/j.trip.2020.100128.

Magnusson, Thomas, and Christian Berggren. 2018. "Competing Innovation Systems and the Need for Redeployment in Sustainability Transitions." Technological Forecasting and Social Change 126:217-30. doi: 10.1016/j.techfore.2017.08.014.

Malça, João, António Coelho, and Fausto Freire. 2014. "Environmental Life-Cycle Assessment of Rapeseed-Based Biodiesel: Alternative Cultivation Systems and Locations.” Applied Energy 114:837-44. doi: 10.1016/j.apenergy.2013.06.048.

Markard, Jochen, Marko Hekkert, and Staffan Jacobsson. 2015. "The Technological Innovation Systems Framework: Response to Six Criticisms." Environmental Innovation and Societal Transitions 16:76-86. doi: 10.1016/j.eist.2015.07.006.

Markard, Jochen, Martin Stadelmann, and Bernhard Truffer. 2009. "Prospective Analysis of Technological Innovation Systems: Identifying Technological and Organizational Development Options for Biogas in Switzerland." Research Policy 38(4):655-67. doi: 10.1016/j.respol.2009.01.013.

Markard, Jochen, and Bernhard Truffer. 2006. "Innovation Processes in Large Technical Systems: Market Liberalization as a Driver for Radical Change?" Research Policy 35(5):609-25. doi: 10.1016/j.respol.2006.02.008.

Mauser, Wolfram, Gernot Klepper, Martin Rice, Bettina Susanne Schmalzbauer, Heide Hackmann, Rik Leemans, and Howard Moore. 2013. "Transdisciplinary Global Change Research: The Co-Creation of Knowledge for Sustainability." Current Opinion in Environmental Sustainability 5(3-4):420-31. doi: 10.1016/j.cosust.2013.07.001.

Meadows, Donella. 2015. Thinking in Systems. Chelsea Green Publishing Co.

Mensah, Justice. 2019. "Sustainable Development: Meaning, History, Principles, Pillars, and Implications for Human Action: Literature Review" edited by S. Ricart Casadevall. Cogent Social Sciences 5(1). doi: 10.1080/23311886.2019.1653531. 
Mignon, Ingrid, and Anna Bergek. 2016. "System- and Actor-Level Challenges for Diffusion of Renewable Electricity Technologies: An International Comparison." Journal of Cleaner Production 128:105-15. doi: 10.1016/j.jclepro.2015.09.048.

Mirata, Murat, Mats Eklund, and Andreas Gundberg. 2017. Industrial Symbiosis and Biofuels Industry: Business Value and Organisational Factors within Cases of Ethanol and Biogas Production. The Swedish Knowledge Centre for Renewable Transportation Fuels.

Möller, Kurt, and Torsten Müller. 2012. "Effects of Anaerobic Digestion on Digestate Nutrient Availability and Crop Growth: A Review: Digestate Nutrient Availability." Engineering in Life Sciences 12(3):242-57. doi: 10.1002/elsc.201100085.

Negro, Simona O., Marko P. Hekkert, and Ruud E. Smits. 2007. "Explaining the Failure of the Dutch Innovation System for Biomass Digestion-A Functional Analysis." Energy Policy 35(2):925-38. doi: 10.1016/j.enpol.2006.01.027.

Negro, Simona O., Roald A. A. Suurs, and Marko P. Hekkert. 2008. "The Bumpy Road of Biomass Gasification in the Netherlands: Explaining the Rise and Fall of an Emerging Innovation System.” Technological Forecasting and Social Change 75(1):57-77. doi: 10.1016/j.techfore.2006.08.006.

Ness, Barry, Evelin Urbel-Piirsalu, Stefan Anderberg, and Lennart Olsson. 2007.

"Categorising Tools for Sustainability Assessment." Ecological Economics 60(3):498-508. doi: 10.1016/j.ecolecon.2006.07.023.

Niskanen, Johan, Jonas Anshelm, and Duncan McLaren. 2020. "Local Conflicts and National Consensus: The Strange Case of Circular Economy in Sweden." Journal of Cleaner Production 261:121117. doi: 10.1016/j.jclepro.2020.121117.

Noel, Lance, and Regina McCormack. 2014. “A Cost Benefit Analysis of a V2G-Capable Electric School Bus Compared to a Traditional Diesel School Bus." Applied Energy 126:246-55. doi: 10.1016/j.apenergy.2014.04.009.

Norton, Bryan G. 2005. Sustainability: A Philosophy of Adaptive Ecosystem Management. Chicago, US: University of Chicago Press.

Nutt, Paul C. 2011. "Making Decision-making Research Matter: Some Issues and Remedies." Management Research Review 34(1):5-16. doi: 10.1108/01409171111096441.

Olsson, Mats-Olov, and Gunnar Sjöstedt. 2004. Systems Approaches and Their Application. Dordrecht: Springer.

Osorio-Tejada, Jose Luis, Eva Llera-Sastresa, and Sabina Scarpellini. 2017. “A Multi-Criteria Sustainability Assessment for Biodiesel and Liquefied Natural Gas as Alternative Fuels in Transport Systems." Journal of Natural Gas Science and Engineering 42:169-86. doi: 10.1016/j.jngse.2017.02.046.

Ottosson, Mikael, Thomas Magnusson, and Hans Andersson. 2020. "Shaping Sustainable Markets-A Conceptual Framework Illustrated by the Case of Biogas in Sweden." Environmental Innovation and Societal Transitions 36:303-20. doi: 10.1016/j.eist.2019.10.008.

Pachauri, R. K., Leo Mayer, and Intergovernmental Panel on Climate Change, eds. 2015. Climate Change 2014: Synthesis Report. Geneva, Switzerland: Intergovernmental Panel on Climate Change.

Parra, David, Xiaojin Zhang, Christian Bauer, and Martin K. Patel. 2017. “An Integrated Techno-Economic and Life Cycle Environmental Assessment of Power-to-Gas Systems." Applied Energy 193:440-54. doi: 10.1016/j.apenergy.2017.02.063.

Peedu, Karin, and Helena Meier. 2020. Driftformer: Kommuner Och Regioner. Sveriges kommuner och regioner.

Piwowar, Arkadiusz, Maciej Dzikuć, and Janusz Adamczyk. 2016. "Agricultural Biogas Plants in Poland - Selected Technological, Market and Environmental Aspects." 
Renewable and Sustainable Energy Reviews 58:69-74. doi: 10.1016/j.rser.2015.12.153.

Prussi, M., M. Yugo, L. De Prada, M. Padella, and Edwards. 2020. JEC Well-To-Wheels Report V5. EYR 30284 EN. Luxembourg: Publications Office of the European Union.

Raheem, Abdul, Pepijn Prinsen, Arun K. Vuppaladadiyam, Ming Zhao, and Rafael Luque. 2018. "A Review on Sustainable Microalgae Based Biofuel and Bioenergy Production: Recent Developments." Journal of Cleaner Production 181:42-59. doi: 10.1016/j.jclepro.2018.01.125.

Rip, Arie, and René Kemp. 1998. “Technological Change.” Pp. 327-299 in Human Choice and Climate Change 2. Columbus, Ohio: Battelle Press.

Rittel, Horst W. J., and Melvin M. Webber. 1973. "Dilemmas in a General Theory of Planning." Policy Sciences 4(2):155-69.

Rotmans, Jan, René Kemp, and Marjolein van Asselt. 2001. "More Evolution than Revolution: Transition Management in Public Policy." Foresight 3(1):15-31. doi: 10.1108/14636680110803003.

Scarlat, Nicolae, Jean-François Dallemand, and Fernando Fahl. 2018. "Biogas: Developments and Perspectives in Europe." Renewable Energy 129:457-72. doi: 10.1016/j.renene.2018.03.006.

Schot, Johan, and Frank W. Geels. 2008. "Strategic Niche Management and Sustainable Innovation Journeys: Theory, Findings, Research Agenda, and Policy.” Technology Analysis \& Strategic Management 20(5):537-54. doi: 10.1080/09537320802292651.

Sehatpour, Mohammad-Hadi, Aliyeh Kazemi, and Hesam-eddin Sehatpour. 2017.

"Evaluation of Alternative Fuels for Light-Duty Vehicles in Iran Using a MultiCriteria Approach.” Renewable and Sustainable Energy Reviews 72:295-310. doi: 10.1016/j.rser.2017.01.067.

Shenton, Andrew K. 2004. "Strategies for Ensuring Trustworthiness in Qualitative Research Projects.” Education for Information 22(2):63-75. doi: 10.3233/EFI-2004-22201.

Shirazi, Yosef, Edward Carr, and Lauren Knapp. 2015. "A Cost-Benefit Analysis of Alternatively Fueled Buses with Special Considerations for V2G Technology." Energy Policy 87:591-603. doi: 10.1016/j.enpol.2015.09.038.

Smith, Adrian, and Rob Raven. 2012. "What Is Protective Space? Reconsidering Niches in Transitions to Sustainability." Research Policy 41(6):1025-36. doi:

10.1016/j.respol.2011.12.012.

Smith, Adrian, Jan-Peter Voß, and John Grin. 2010. "Innovation Studies and Sustainability Transitions: The Allure of the Multi-Level Perspective and Its Challenges." Research Policy 39(4):435-48. doi: 10.1016/j.respol.2010.01.023.

Smith, V. H., G. D. Tilman, and J. C. Nekola. 1999. "Eutrophication: Impacts of Excess Nutrient Inputs on Freshwater, Marine, and Terrestrial Ecosystems." Environmental Pollution 18.

Stock, Paul, and Rob J. F. Burton. 2011. "Defining Terms for Integrated (Multi-Inter-TransDisciplinary) Sustainability Research.Pdf.” Sustainability 1090-1113. doi: 10.3390/su3081090.

Stoknes, K., F. Scholwin, W. Krzesiński, E. Wojciechowska, and A. Jasińska. 2016. "Efficiency of a Novel 'Food to Waste to Food' System Including Anaerobic Digestion of Food Waste and Cultivation of Vegetables on Digestate in a BubbleInsulated Greenhouse." Waste Management 56:466-76. doi: 10.1016/j.wasman.2016.06.027.

Surroop, Dinesh, Zumar M. A. Bundhoo, and Pravesh Raghoo. 2019. "Waste to Energy through Biogas to Improve Energy Security and to Transform Africa's Energy Landscape." Current Opinion in Green and Sustainable Chemistry 5. 
Sushandoyo, Dedy, and Thomas Magnusson. 2014. "Strategic Niche Management from a Business Perspective: Taking Cleaner Vehicle Technologies from Prototype to Series Production." Journal of Cleaner Production 74:17-26. doi: 10.1016/j.jclepro.2014.02.059.

Sveriges Kommuner och Regioner. 2021a. “Kommunernas åtaganden.” Retrieved June 8, 2021

(https://skr.se/skr/tjanster/kommunerochregioner/faktakommunerochregioner/kommun ernasataganden.3683.html).

Sveriges Kommuner och Regioner. 2021b. "Regionernas åtaganden.” Retrieved June 8, 2021 (https://skr.se/skr/tjanster/kommunerochregioner/faktakommunerochregioner/regioner nasataganden.27748.html).

Swedish Association of Local Authorities and Regions. 2015. Öppna jämförelser Kollektivtrafik 2015.

Swedish Energy Agency. 2016. "Biogas Statistics 2015 (Dataset)."

Swedish Energy Agency. 2020. Energiläget 2020. ET 2020:1.

Swedish Environmental Protection Agency. 2021. "Växthusgaser, Utsläpp Från Inrikes Transporter." Retrieved August 2, 2021

(https://www.naturvardsverket.se/PageFiles/14886/6210_sv.pdf).

Swedish Government Official Reports. 2019. Mer biogas!: för ett hållbart Sverige.

Swedish Waste Management Association. 2008. Den Svenska Biogaspotentialen Från Inhemska Råvaror [The Swedish Biogas Potential from Domestic Raw Materials]. (2008).

Testa, Francesco, Eleonora Annunziata, Fabio Iraldo, and Marco Frey. 2016. "Drawbacks and Opportunities of Green Public Procurement: An Effective Tool for Sustainable Production." Journal of Cleaner Production 112:1893-1900. doi: 10.1016/j.jclepro.2014.09.092.

Theobald, Olivier. 2015. Country Report France. French Agency for Environment and Energy Management, for IEA Bioenergy Task 37 (2015).

Tracy, Sarah J. 2010. "Qualitative Quality: Eight 'Big-Tent' Criteria for Excellent Qualitative Research.” Qualitative Inquiry 16(10):837-51. doi: 10.1177/1077800410383121.

Tzeng, Gwo-Hshiung, Cheng-Wei Lin, and Serafim Opricovic. 2005. "Multi-Criteria Analysis of Alternative-Fuel Buses for Public Transportation." Energy Policy 33(11):1373-83. doi: 10.1016/j.enpol.2003.12.014.

UN General Assembly. 2015. Sustainable Development Goals.

United Nations. 2019. "About the Sustainable Development Goals.” United Nations Sustainable Development. Retrieved March 15, 2019

(https://www.un.org/sustainabledevelopment/sustainable-development-goals/).

Vahdani, Behnam, M. Zandieh, and R. Tavakkoli-Moghaddam. 2011. "Two Novel FMCDM Methods for Alternative-Fuel Buses Selection." Applied Mathematical Modelling 35(3):1396-1412. doi: 10.1016/j.apm.2010.09.018.

Vitousek, Peter M., John D. Aber, Robert W. Howarth, Gene E. Likens, Pamela A. Matson, David W. Schindler, William H. Schlesinger, and David G. Tilman. 1997. "Technical Report: Human Alteration of the Global Nitrogen Cycle: Sources and Consequences.” Ecological Applications 7(3):737-50. doi: 10.2307/2269431.

Weimer-Jehle, Wolfgang, Jens Buchgeister, Wolfgang Hauser, Hannah Kosow, Tobias Naegler, Witold-Roger Poganietz, Thomas Pregger, Sigrid Prehofer, Andreas von Recklinghausen, Jens Schippl, and Stefan Vögele. 2016. "Context Scenarios and Their Usage for the Construction of Socio-Technical Energy Scenarios.” Energy 111:95670. doi: 10.1016/j.energy.2016.05.073. 
Wellinger, Arthur, Jerry D. Murphy, and David Baxter. 2013. The Biogas Handbook: Science, Production and Applications. Woodhead Publishing.

Wirth, Steffen, Jochen Markard, Bernhard Truffer, and Harald Rohracher. 2013. "Informal Institutions Matter: Professional Culture and the Development of Biogas Technology." Environmental Innovation and Societal Transitions 8:20-41. doi: 10.1016/j.eist.2013.06.002.

World Bioenergy Association. 2013. "Biogas - an Important Renewable Energy Source." World Commission on Environment and Development. 1987. Our Common Future. Oxford University Press.

WSP. 2013. Realiserbar biogaspotential i Sverige år 2030 genom rötning och förgasning. 


\section{Papers}

The papers associated with this thesis have been removed for copyright reasons. For more details about these see:

http://urn.kb.se/resolve?urn=urn:nbn:se:liu:diva-179009 


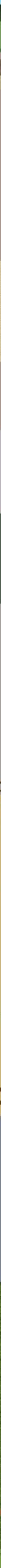

